\title{
Compositio corporum. Renaissance der Bio Art
}

\author{
FRANK FEHRENBACH
}




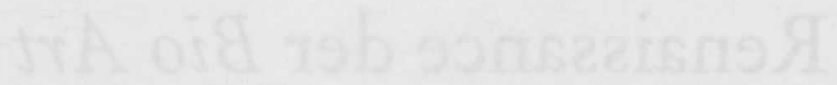


Wenn nach über hundert Jahren Moderne - und das heißt auch: nach über hundert Jahren Transgression, Tabubruch, Entgrenzung, nach dem radikal Ephemeren, der verweigerten Aussage, nach Verabschiedung und Reanimation von Traditionen, nach dem Durchspielen scheinbar jeder Variante, jeder Geste, jedes Materials und Nicht-Materials - wenn inmitten der alltäglichen kulturellen Beschleunigungskrise selbst professionelle Rhapsoden der Avantgarde verstört oder ablehnend reagieren ${ }^{1}$, dann muß es einem Teil der Kunst wieder einmal gelungen sein, eine bislang unbemerkte Grenze verschoben zu haben. Das ist erfreulich, denn die Abnutzung ihrer individualistischen Gesten, ihre Kanonverliebtheit, ihre Marktkonformität und nicht zuletzt ihre akademische Massenpopularität haben die Kritik der Gegenwartskunst längst zu einem der konservativsten Felder der Kunstgeschichte gemacht. Wer heute Kunst als Irritation, Herausforderung oder Abenteuer erfahren möchte, ist gut beraten, aus der raunenden Menschenschlange vor MoMa-Reliquien auszuscheren und sich stattdessen mit den fremden Wahrnehmungsformen, unvertrauten Materialien und verschollenen Narrativen von - beispielsweise - Mittelalter und Früher Neuzeit auseinanderzusetzen. Oder aber mit Bio Art.

1 Vgl. etwa R. Hoppe-Sailer: Bioplay. Medien - Simulation - Natur?, in: H. W. Ingensiep und A. Eusterschulte (Hg.): Philosophie der natürlichen Mitwelt. Festschrift Klaus-Michael Meyer-Abich, Würzburg 2002, S. 257-272. 
Die Bezeichnung ist eher willkürlich, denn in unserer doch keineswegs um branding verlegenen Kultur hat die marginale, aber mit maximaler Öffentlichkeitswirkung agierende Tendenz, um die es hier geht, noch immer keinen rechten Namen. Im Angebot befinden sich auch Transgenic Art, l'art biotech' oder DNArt. Die neue Kunst entstand im Windschatten der zahlreichen Ausstellungen in den neunziger Jahren, die sich mit den Transformationen des menschlichen Körpers im Zeichen von Virtual Reality, Prothetik und Gentechnologie befaßten. Ein entscheidender Impuls ging dabei von der Ars electronica in Linz aus, die 1993 mit Genetische Kunst - Künstliches Leben aufhorchen ließ. Linz blieb dem Thema treu; 1996 folgte Die Zukunft der Evolution und mit Life Science 1999 war auch konzeptuell ein Höhepunkt erreicht. Parallel lud die Bundeskunsthalle zu Gen-Welten. Prometheus im Labor? ein, mit einem politisch korrekten Fragezeichen. Die USA zogen mit Paradise now - Picturing the Genetic Revolution im Exit Art Museum von New York nach, kaum zufällig im Jahr der feierlichen Ankündigung von Bill Clinton und Craig Venter, das menschliche Genom annähernd vollständig entschlüsselt zu haben. In Duisburg folgte 2001 Unter der Haut - Transformationen des Biologischen in der zeitgenössischen Kunst (Lehmbruck-Museum) und im Kunsthaus Meran, mit einem Versuch, dem Neuen einen Namen zu geben, DNArt - Gen-Ethik und Visionen. Berkeley und Nantes setzten 2003 weitere Akzente mit Gene(sis): Contemporary Art Explores Human Genomics (Berkeley Art Museum) und L'art biotech' (Le Lieu Unique). ${ }^{2}$

2 Vgl. zum Thema außer den Katalogen der genannten Ausstellungen mit ihren teilweise ausgezeichneten Beiträgen zusammenfassend: E. K. Levy: Contemporary art and the genetic code, New models and methods of representation, in: Art Journal. Contemporary Art and the Genetic Code 55/1, 1996, S. 20-24; R. Shapiro: DNA, art, and hereafter, in: Art Journal. Contemporary Art and the Genetic Code 55/1, 1996, S. 75-78; O. Grau: „Lebendige Bilder“ schaffen. Virtuelle Realität, Artificial Life und Transgenic Art, in: B.-M. Baumunk und J. Joergens (Hg.): Dschungel. Sammeln, Ordnen, Bewabren: Von der Vielfalt des Lebens zur Kultur der Natur. 7 Hügel - Bilder und Zeichen des 21. Jahrhunderts, Teil 2, Berlin 2000, S. 47-53; I. Reichle: Kunst und Biomasse. Zur Verschränkung von Biotechnologie und Medienkunst in den 90er Jah- 
Worum geht es? Mit dem großflächigen Anbau von transgenen Nahrungsmitteln seit etwa 1995 und der Geburt des ersten geklonten höheren Säugetieres, des Schafes Dolly durch Ian Wilmut 1997 waren spektakuläre biotechnische Innovationen Wirklichkeit geworden. Annähernd gleichzeitig überraschten Künstler wie Edoardo Kac oder Joe Davis die Öffentlichkeit mit im Labor erzeugten transgenen Lebewesen, die sie zum Kunstwerk erklärten.

Daß der kulturelle Vorgang, dem ich mich hier ganz skizzenhaft widmen möchte, unweigerlich polarisiert, verwundert nicht. Mein Ausgangspunkt sind nicht die schockierenden Körpertransformationen, die einige Künstler der Gegenwart an sich selbst vornehmen - etwa die kombinatorische Schönheitschirurgie der Französin Orlan, eine Umdeutung des additiven Kanons des Zeuxis, bei dem nun frühneuzeitliche Kunstwerke als Vorbild dienen: „So besitzt sie mittlerweile die Stirn von Leonardos Mona Lisa, das Kinn von Botticellis Venus, die Augen von Geromes Psyche und den Mund von Bouchers Europa." (Söke Dinkla). ${ }^{3}$ Oder die posthumane Prothesenkunst des Australiers Stelarc, der sich selbst in einen Cyborg verwandelt, künstliche Gliedmaßen und zusätzliche Organe ansetzt, während die Hohlräume seines Körperinneren technoide Skulpturen bevölkern. ${ }^{4}$ All das setzt lediglich die Körperinszenierungen der Body Art fort und steht damit in einer langen Tradition, in der sich der Künstler selbst zum Kunstwerk er-

ren, in: Kritische Berichte 29/1, 2001, S. 23-33; Transgene Kunst: Klone und Mutanten. Kunstforum International 157, Nov./Dez. 2001. Die gerade erschienene Dissertation von Ingeborg Reichle: Kunst aus dem Labor. Zum Verbältnis von Kunst und Wissenschaft im Zeitalter der Technoscience, Wien 2005, konnte hier leider nicht mehr berücksichtigt werden.

3 Vgl. zuletzt: Orlan, Ausstellungskatalog, Fonds Régional d'Art Contemporain des Pays de la Loire, Carquefou (2002/2003) und Centre National de la Photographie, Paris (2004), Paris 2004.

4 Vgl. H. Caygill: Stelarc and the Chimera. Kant's Critique of Prosthetic Judgment, in: The Art Journal 56/1, 1997, S. 46-51; S(t)imulations: 'the artist also has something to say' - listening to Stelarc. The artist in conversation with Robert Ayers, in: K. Mey (Hg.): Sculpsit. Contemporary artists on sculpture and beyond, Manchester 2001, S. $127-140$. 
klärt. Dies ist Frucht einer bis in die Frühe Neuzeit zurückreichenden Autonomiebewegung, in deren Verlauf es geradezu unausweichlich erschien, den künstlerischen Gestus zu habitualisieren, auf die eigene Biographie und zugleich pathognomisch auf den eigenen Körper auszudehnen, in eigentümlicher Fortdeutung des alten Florentiner Renaissancediktums, wonach jeder Maler stets sich selbst malt. ${ }^{5}$ Spätestens mit der aufgeklärten Genie-Ästhetik wurde dieses Spiegelverhältnis festgeschrieben: „Alles, was der Dichter uns geben kann, ist seine Individualität", schrieb Schiller anläßlich seiner Kritik von Gottfried August Bürgers Gedichten, und fügte vielsagend hinzu: „Diese muß es also werth seyn, vor Welt und Nachwelt ausgestellt zu werden." 6

Darum soll es, wie gesagt, nicht gehen. Das lebendige Material der aktuellen Bio Art ist der tierische, seltener der pflanzliche ${ }^{7}$ Organismus, aber es dürfte nicht mehr lange dauern, bis es auch hier zu Verschmelzungen mit der Body Art kommt und die ersten Künstler auf die Autonomie ihrer Selbstformung pochen (etwa als transgene Klone), die ältere Feststellung des neuplatonischen Renaissancephilosophen Pico della Mirandola aktualisierend, wonach letztlich jeder Mensch plastes et fictor, Bildhauer und Dichter von sich selbst sei. ${ }^{8}$ Man liegt wohl mit der Erwartung nicht falsch,

5 Vgl. M. Kemp: ,Ogni dipintore dipinge sé‘: A Neoplatonic Echo in Leonardo’s Art Theory?, in: C. H. Clough (Hg.), Cultural Aspects of the Italian Renaissance: Essays in Honour of Paul Oskar Kristeller, Manchester 1976, S. 311-323; F. Zöllner: ,Ogni pittore dipinge séc. Leonardo da Vinci and ,Automimesis', in: M. Winner ( $\mathrm{Hg}$.): Der Künstler über sich in seinem Werk, Weinheim 1992, S. 137-160. Zum Fortwirken der Formel im 17. Jahrhundert: Ph. Sohm: Caravaggio's deaths, in: The Art Bulletin LXXXIV/3, 2002, S. 449-468 (S. 467-468, Anm. 97).

6 F. Schiller: Über Bürgers Gedichte, in: Schillers sämmtliche Werke in zwölf Bänden, Stuttgart und Tübingen 1838, Bd. 12, S. 341-357 (S. 343).

7 Vgl. dazu: B. Nemitz: trans / plant. Living vegetation in contemporary art, Ostfildern (Ruit) 2000.

8 De hominis dignitate XXII. 
daß es neben dem Sport (Gendoping) die Kunst sein wird, in deren Schutzzone die ersten androiden Chimären auftreten werden. ${ }^{9}$

Werfen wir zunächst einen Blick auf zwei Künstler, die Lebewesen als Kunstwerke herstellen, ohne jedoch in das Genom ihrer Kunstorganismen einzugreifen: George Gessert, der Schwertlinien züchtet und Marta de Menezes, die die Flügelfärbung ihrer Schmetterlinge im Larvenstadium manipuliert (Abb. 1). ${ }^{10}$ Beide Künstler können mit dem traditionellen heroischen Vokabular der Moderne als Grenzgänger gewertet werden und bleiben mit ihrem künstlerischen Material im Rahmen kulturell akzeptierter Praktiken. Niemand käme auf die Idee, bei diesen kurzlebigen Biofakten ${ }^{11}$ die kulturkritische Reißleine zu ziehen, obwohl es gerade Gessert ist, der in seinen vielzitierten Texten der späten neunziger Jahre die Kontinuität zwischen traditioneller Züchtung und aktueller, „DNA involvierender“ BioArt unterstreicht.

Eine der grundlegenden Bedingungen für den Erfolg der aktuellen Biotechnologie (Stichwort: Präimplantationsdiagnostik) beruht auf ihren Möglichkeiten, ethische Oppositionslinien durch ,Vergrößerung' durchlässig zu machen, Raum und Zeit zu digitalisieren. Die Kontinuität der scala naturae wird zur Herstellungsoption, und das ,Halblebendige' (semi-living) gerät verstörend in den Blick. Die australische Künstlergruppe Tissue, Culture E Art (kurz TC\&A - Oron Catts, Ionat Zurr und Guy Ben-Ary) arbeitet seit den späten neunziger Jahren mit Zellgeweben, die mithilfe des gentechnischen Labors zur Matrix lebender Körperzellen werden. TC\&A befassen sich mit dem sog. tissue engineering und wollen auch ihrem Landsmann

9 Zur Aufregung um die ,Göttinger Chimäre‘, möglicherweise verursacht durch die unbeabsichtigte Rückentwicklung einer menschlichen Nervenzelle in eine undifferenzierte Stammzelle, vgl. Ch.Schwägerl: Stammzellenforschung. Die Göttinger Chimäre, in: FAZNet, 2.5.2005.

10 Vgl. G. Gessert: Eine Geschichte der DNA-involvierenden Kunst, in: G. Stocker und Ch. Schöpf (Hg.): Ars Electronica 99. Life Science, Wien und New York 1999, S. 236-244; ders., Notes on Genetic Art, in: Leonardo 26/3, 1993, S. 205-211; http:// www.martademenezes.com.

11 Vgl. N. Karafyllis (Hg.): Biofakte. Versuch über den Menschen zwischen Artefakt und Lebewesen, Paderborn 2003. 
Stelarc zum gewünschten dritten $\mathrm{Ohr}$ (Abb.2) verhelfen, das allerdings nicht hören wird, sondern, mit einem Miniaturempfänger ausgestattet, dem wirklichen Organ Nachrichten aus dem Internet zuflüstern soll. (Wird man die mit „öberen Eingießungen“ [Dürer] Begnadeten künftig an der Zahl ihrer Ohren erkennen?) Eine 2003 auch in Nantes zu sehende Arbeit von TC\&A verwendet sogenannte worry dolls, die kleinen Kindern an manchen Orten unters Kopfkissen gelegt werden, nachdem sie sich fest etwas gewünscht haben, auf daß es sich erfülle (Abb. 3). ${ }^{12}$ TC\&A umhüllen nun diese winzigen Artefakte sorgfältig mit Zellgeweben, denen im Labor Keimzellen einer Maus eingepflanzt wurden. Unter sterilen Bedingungen ersetzen die Mäusezellen nach und nach ihr Medium, überwuchern die Wunschpüppchen und wachsen innerhalb ihrer Nährlösung zu formlosen Gebilden aus. Der Betrachter, der sich dem ,halblebendigen' Gebilde mit dem Vergrößerungsglas nähert, wird Zeuge eines Wucherungsprozesses, bei dem die tote anthropomorphe Form der Puppen allmählich überdeckt wird durch einen halb transparenten, kontingent ausgreifenden , Organismus'. Täglich können die Zuschauer einem sogenannten feeding ritual beiwohnen, bei dem die Nährlösung der Ampullen ersetzt wird. Am Ende der Ausstellung findet konsequenterweise das sogenannte killing ritual statt. Die ,halblebendigen' Gebilde werden aus ihrer Nährlösung genommen und von den Zuschauern berührt. Durch die nichtsterile Luft und die Berührung sterben die Zellkulturen rasch ab; sie werden Opfer feindlichen Lebens.

In der anschaulich zwingenden Umdeutung älterer Phantasmen erweist sich Qualität und Komplexität künstlerischer Hervorbringungen. Die ,halblebendigen' Skulpturen von TC\&A modifizieren eines der wirkmächtigsten produktionsästhetischen Paradigmata, die Belebung der Elfenbeinstatue des Bildhauers Pygmalion. ${ }^{13}$ Der Verwandlungsmythos wird in Ovids Metamorphosen (X, 243-297) prominent entfaltet und invertiert dort seinerseits die lange Reihe der Transformationen zwischen lebendigem

12 Vgl. http://www.tca.uwa.edu.au/ars/main_frames.html

13 Vgl. dazu jetzt umfassend: V. I. Stoichita: Simulacra. The Pygmalion Effect from Ovid to Hitchcock, Chicago 2005 (im Druck). 
Organismus und totem Bild (Versteinerung); eine künstlerische Verlebendigungsleistung, in der sich Ovids eigener narrativer Anspruch widerspiegelt. Vom erotischen Vorzeichen bei Ovid und innerhalb der langen Tradition ,lebendiger' Skulpturen ist bei TC\&A nichts mehr sichtbar, wohl aber vom dialektischen Schatten des artifiziellen Lebens - der Sterilität -, die Pygmalions inzestuöse Genealogie bis zum Urenkel Adonis prägt. ${ }^{14}$

Der Akzent liegt nun auf der technischen Herstellung von Leben; kein Gebet eines ins eigene Werk verliebten Künstlers, den Venus gnädig erhört, auf daß das harte Material sich unter den warmen Händen erweiche. Die Invokation der Götter entfällt; der ,alchemistische` Hintergrund drängt sich stattdessen auf. Die Selbstermächtigung des Bildhauers, Werke zu schaffen, die so lebendig sind, daß ihre tatsächliche Beseelung in jedem Moment zu erwarten ist, findet in der Renaissance statt. Sicher, dort geht es um ästhetische Lebendigkeit. Die Grenzen sind dabei aber durchlässig; Materialkenntnis, pneumatische Manipulation und göttliche Assistenz gehen Hand in Hand. Benvenuto Cellini beispielsweise inszeniert den Guß der Persens-Medusa-Gruppe der Piazza della Signoria im Rückblick als nächtliches, demiurgisches Spektakel. Erst mit seiner Anrufung des Auferstandenen gelingt es dem fieberkranken Künstler, die Bronze zum Fließen zu bringen und, wie er schreibt, die Statue zu animieren, wobei mit der allmählich abkühlenden Materie auch seine eigene Temperatur nachläßt. ${ }^{15}$ Anders als im antiken Mythos, müssen die ,halblebendigen' Skulpturen von TC\&A aber vor jedem Kontakt mit der Welt des Zuschauers geschützt werden; seine Berührung wirkt tödlich. Und auch der Prozeß des allmählichen Formverlusts als Wucherung kehrt den antiken Mythos um. Mit den kleinen Dimensionen der Gebilde invertieren TC\&A zugleich das Paradigma der lebensgroßen, besser kolossalen antiken und neuzeitlichen Statue. ${ }^{16}$ All das macht jene unheimlichen Horizonte sichtbar, die rezeptionsgeschichtlich unter den erotischen Gehalten der Mythe begraben wur-

14 Vgl. W. Menninghaus: Das Versprechen der Schönheit, Frankfurt/M. 2003, S. 40-47.

15 B. Cellini: La vita, hrsg. von L. Bellotto, Parma 1996, S. 668-675. Umfassend zum Vorgang: M. Cole: Cellini's blood, in: The Art Bulletin 81, 1999, S. 215-235.

16 Vgl. V. Bush: The colossal sculpture of the Cinquecento, New York 1976. 
den; Horizonte, in denen die Puppe zugleich für den Lebenden einstehen konnte, Tauschvorgänge möglich waren. ${ }^{17}$ Umso schmerzlicher ist es, daß TC\&A in charakteristischer Neigung zu Überdetermination und Verniedlichung ihre eigene Idee durch zu intensive konzeptionelle Zuwendung töten. Nun sollen die Püppchen, alphabetisch benannt, für unsere konkreten Ängste vor der Biotechnologie stehen, die der Besucher elektronischen worry machines mitteilen kann. Die Aufhängung ist Kitsch und kann mit einem ihrer Vorbilder, Lim Young Suns Room of the Host (1998/99) und seinen unheimlich wispernden Silikon-Präparaten nicht konkurrieren.

Dem Brasilianer Edoardo Kac gelang es vor drei Jahren, mit dem Kaninchen Alba so etwas wie die Ikone der Transgenen Kunst zu schaffen (Abb.4). Es handelt sich um eine zugleich simple und weitreichende Geste. Das französische Labor, das für Kac angeblich das phosphoreszierende Quallen-Gen GFP in das Genom des Albinos schleuste, tat nur, was seit längerem wissenschaftliche Praxis ist. Bereits 1971 wurden Körperzellen eines Hasen mit dem Leuchtprotein einer Meeresalge präpariert. Im Rückblick auf das Jahr 2003 stellte die FAZ zahlreiche transgene GFP-Tiere vor, die kurz vor der kommerziellen Verwertung stehen, beispielsweise als schwimmende Leuchtstifte im heimischen Aquarium (Abb.5). Der Farbeffekt ergibt sich nur unter UV-Licht. Alba und ihren Artgenossen entgeht die Pointe also vermutlich, ebenso wie den leuchtenden Schweinen, die dem Fleischproduzenten irgendwelche Vorteile verschaffen sollen.

Die Existenz von Alba selbst ist allerdings fraglich, denn Biologen verweisen darauf, daß GFP nur in der Haut, nicht in den Haaren der Tiere aktiv wird. ${ }^{18} \mathrm{Kac}$, der den Nager bislang nur fotografisch präsentierte, stellte bereits vor einigen Jahren das Projekt eines GFP-modifizierten Hundes

17 Ein naheliegendes Beispiel bieten etwa die Puppen, die bei Dosso Dossis Circe (Melissa), Galleria Borghese, Rom (ca. 1515/16) über der Hexe am Baum hängen; vgl. dazu P. Humphreys: Katalogbeitrag in: A. Bayer (Hg.): Dosso Dossi. Pittore di corte a Ferrara nel Rinascimento, Ferrara 1998, S. 114-117.

18 Vgl. dazu K. Philipkoski: Alba, the glowing bunny (12.8.2002; http://www.wired. com/news/medtech/0,1286,54399,00.html). 
vor (GFP K-9), der als Photomontage einen ähnlich überzeugenden Eindruck macht wie das Kaninchen. ${ }^{19}$

Aber die Frage nach der Existenz von Alba kann durchaus offen bleiben. Kac konzeptualisiert seine Kreation geradezu lustvoll. Angeblich wurde er vom Labor daran gehindert, das transgene Wesen im Jahr 2000 in Avignon als Kunstwerk zu präsentieren; eine nicht unwahrscheinliche Vorsichtsmaßnahme angesichts der bestehenden gesetzlichen Restriktionen, die unkontrollierte Auskreuzungen verhindern sollen. Ähnlich wie im Fall der Mona Lisa, die erst durch ihren Raub 1911 - also durch ihre zweijährige Unsichtbarkeit - zur Tempelikone des Louvre wurde, ist auch im Falle von Albas Absenz Bedingung gesteigerter medialer Präsenz. Kac jedenfalls betrieb im Dezember 2002 eine Medienkampagne mit geradezu aufreizend traditionellen Mitteln und klebte in Paris, am folkloristischen Ort der Avantgarde, hunderte von Plakaten, die ihn mit seinem Kaninchen zeigen (das nicht leuchtete) und durch lapidare Beischriften wie Science, Religion, Famille, Art die unterschiedlichen Diskursfelder benennen, an deren Schnittstelle sich das Biofakt befindet (Abb. 6). Zugleich dokumentierte Kac fotografisch das weltweite Presse-Echo in seinem jeweiligen Ambiente. ${ }^{20}$

Der grüne Mümmelmann wurde so zur globalen Ikone, sein Schöpfer zum Freiheitskämpfer. Kac betont immer wieder sein zentrales Anliegen: die Chimäre aus ihrem Laborgefängnis zu befreien und ihr jene familiäre Zuneigung zu gewähren, auf die auch technisch erzeugte Zwitterwesen einen Anspruch hätten. Das niedliche Tierchen erleichtert die Identifikation. Im Handumdrehen wird so aus den kulturellen Beschleunigungsfanatikern der hard sciences ein Orden reaktionärer Tierfeinde. Es waren wohl diese Gründe, die den am Art Institute von Chicago wirkenden Kac Frankreich als location seiner Aktion wählen ließen. So wurde der Schwarze Peter als grünes Kuscheltier über den Atlantik gereicht.

Die politischen Ziele von Kac lassen sich wie folgt zusammenfassen. Erstens: Wir brauchen eine vorurteilsfreie Debatte um genetisch modifi-

19 Vgl. E. Kac: Transgenic Art, in: Ars Electronica 99 [wie Anm. 10], S. 289-296; S. Shaviro: Atomic Dogs, in: Artbyte, März-April 2000, S. 22-23.

20 Vgl. die Texte in http://www.ekac.org/gfpbunny.html. 
zierte Organismen. Zweitens: Wir sollten Lebewesen, deren Erzeugung sich weitgehend technischen Manipulationen verdanken, nicht weniger $\mathrm{Zu}$ neigung entgegenbringen als ihren, natürlichen' Verwandten. Letztlich sei jedes Lebewesen ohnehin ,transgen', wie der Blick auf das menschliche Genom lehre, in dessen Stammesgeschichte ebenfalls fremdartiges Erbgut, beispielsweise von Viren, eingebaut wurde.

Zuneigung, Liebe - die Stereotypien der Haustierhaltung im Dienst der biotechnologischen Revolution, aber „solche Liebe behält stets die Züge einer feudalen Geste“. ${ }^{21}$ Jeder transgene Organismus ein pet - das dürfte selbst entschlossenen, bei E.T. in Mitgefühl schwelgenden Empathikern angesichts von plastikproduzierenden Pflanzen und Ziegen mit Spinnengenen, angesichts künftiger, womöglich aggressiver „Plantimalen“ und „Anomines" schwerfallen. Den bioethischen Hintergrund bevölkern bei Kac in Wahrheit die harmlosen, farbenfrohen Tiermensch-Chimären des Pop (Comic). Schon in Vilém Flussers prophetischem Gründungstext der transgenen Kunst von 1988, Curie's Children, wird dieser Hintergrund expliziert. Flusser fragt provozierend, warum die Pferde noch immer nicht fluoreszieren und erklärt: „Das Disneyland wird von bunten Tieren wimmeln, damit die Menschen darin nicht vor Langeweile sterben ". ${ }^{22}$

Aber die Aktion von Kac ist ikonologisch dichter, als es der durchaus redselige Künstler selbst wahrhaben will. Hinter Pink Panther und Konsorten werden erstaunliche Vorbilder sichtbar, die Kac charakteristisch umdeutet. Mit der Plakataktion wird listig auf Joseph Beuys verwiesen, der 1965 in der Galerie Schmela (Düsseldorf) „die Bilder“ einem toten Hasen erklärte (Abb. 7), während Kac Bilder eines lebenden Kaninchen produziert, dem er nichts zeigen darf. Nur der Gestus der elterlichen Fürsorge ist derselbe geblieben; den Tod hat die frivole Kunst des Edoardo Kac nicht

21 P. Sloterdijk: Stimmen für die Tiere - Phantasie über animalische Repräsentation, in: R. Haslinger (Hg.): Herausforderung Tier. Von Bewys bis Kabakov, Ausstellungskatalog, Städtische Galerie, Karlsruhe (2000), München u. a. 2000, S. 132.

22 V. Flusser: Curie's Children, in: Artforum 26/7, 1988, S. 14-15. 
im Programm. "It's a strictly formal comparison", beteuert Kac; “I'm talking about enabling life." 23

Würden sich Albinos gerne quallengrün leuchten sehen? Das ist eine absurde Frage, solange man die blauen Pferde Franz Marcs nicht in die Ahnenreihe von Alba stellt. Aber der bayerische Maler schrieb: „Wie sieht ein Pferd die Welt oder ein Adler, ein Reh oder ein Hund? Wie armselig, seelenlos ist unsere Konvention, Tiere in eine Landschaft zu setzen, die unsren Augen zugehört, statt uns in die Seele des Tieres zu versenken?“ 24 Und schon scheitert jeder Vergleich mit GFP Bunny. Das Tier wurde für menschliche Augen verändert, die nur unter speziellen künstlichen Lichtbedingungen sein geisterhaftes Schimmern wahrnehmen, jenes Grün der Nachtsichtgeräte, das auch die zeitgenössische Kriegsberichterstattung dominiert. "Alba should get a good lawyer and sue Kac for a wrongful life suit." 25

Dennoch sollte zweierlei nicht übersehen werden. Erstens: Mit der Erklärung eines genetisch veränderten Organismus zum Kunstwerk geht Kac weit über die Verwendung von Tieren im künstlerischen, performativen Kontext des 20. Jahrhunderts hinaus. Nach I cavalli von Jannis Kounellis (Rom 1969) oder I like America and America likes me von Joseph Beuys (New York 1974) verschwanden Pferde und Kojote für immer aus dem Kunstraum. Alba hingegen wird zeitlebens ein ,Werk' bleiben. Es gehört wenig Phantasie dazu, den logisch nächsten Schritt von Kac vorherzusagen: die Erhebung des Urheberanspruchs auf das Tier und gegebenenfalls seine Nachkommen. (Das beteiligte französische Labor beeilt sich inzwischen vorsorglich mit der Erklärung, daß Alba bereits im August 2002 gestorben sei, was Kac jedoch bezweifelt.) ${ }^{26}$ Das grüne Kaninchen könnte in einer Galerie für vermutlich viel Geld verkauft werden; die Schweine,

23 Zit. nach B. Eskin: Building the bioluminescent bunny, in: ARTnews 100/11, Dez. 2001, S. 118-119, hier S. 119.

24 Zit. nach S. Partsch: Franz Marc (1880-1916), Köln 1993, S. 38.

25 D. Hoyt: Edoardo Kac flunks the rabbit test (http://www.ncal.verio.com/ leftcurv/ LC25WebPages/rabbit.html).

26 Vgl. Philipkoski [wie Anm. 18]. 
die Rosemarie Trockel und Carsten Höller auf der vorletzten documenta in Szene setzten, nicht (höchstens in ihrem architektonischen Ensemble). Alba dagegen ist ein Kunstwerk. Einigermaßen betroffen steht man vor der Frage, warum erst 1994 ein Tier - Marc Wallingers Rennpferd - kontextunabhängig zum Real Work of Art erklärt wurde, obwohl Marcel Duchamp bereits 1917 über sein Pissoir schrieb: "Whether Mr Mutt with his own hands made the fountain or not has no importance. He CHOSE it. $\mathrm{He}$ took an ordinary article of life, placed it so that its useful significance disappeared under the new title and point of view - created a new thought for that object." ${ }^{27}$ Die Neuheit des Zugriffs zeigt sich nicht zuletzt daran, daß Tiere in den jüngsten grundlegenden Publikationen Monika Wagners über die Materialien der modernen Kunst - teilweise ja explizit ein Nachruf auf diese Moderne - im Gegensatz zu Pflanzen nirgendwo auftauchen. ${ }^{28}$ Der Leser wird auf Haut, Fleisch, Blut, Haare, Knochen etc. verwiesen, das heißt auf tote Teile des Lebewesens, während die Bio Art auf's lebendige Ganze geht.

Zweitens: Alba ist nicht bloß ein animalisches Ready-made, sondern ein transgenes Wesen, eine Chimäre ${ }^{29}$ - ein Biofakt, das durch die Koppelung der genetischen Information von zwei unterschiedlichen Species entstand, Hase und Qualle. Mit transgenen Tieren arbeitet Kac auch in seinen Installationen The Eigth Day und Genesis. Hier werden Bakterien mit GFP und mit einer vom Künstler kodierten DNA - einem „Künstler-Gen“ - kombiniert. Doch was Kac erzeugen läßt, ist seit langem fester Bestandteil im Imaginarium der aktuellen Kunst und Unterhaltungskultur. Thomas Grünfelds Misfits (Abb. 8) und Matthew Barneys Travestien, Cindy Shermans rekombinierte Hybride oder Iris Schiefersteins unheimliche Mischpräpa-

27 Zit. nach Ch. Harrison und P. Woods (Hg.): Art in theory 1900-2000. An anthology of changing ideas, Malden MA u. a. 2003, S. 252.

28 M. Wagner: Das Material der Kunst. Eine andere Geschichte der Moderne, München 2001; dies. u. a. (Hg.): Lexikon des künstlerischen Materials. Werkstoffe der modernen Kunst von Abfall bis Zinn, München 2002.

29 Vgl. E. Schenkel: Chimären im Buch des Lebens, in: Scheidewege 32, 2002/2003, S. 94-105. 
rate zeugen davon. Im Film lebt von Chimären bekanntlich ein ganzes Genre. Scheinbar färbt Kac bloß die Oberfläche seiner Tiere ein, aber erst wenn der faktische Kern der Manipulation - die ,Kreuzung' jenseits der natürlichen Reproduktionssperre - in den Blick genommen wird, kann es gelingen, den eigentlichen historischen Ursprungsort des künstlerischen Phantasmas zu ermitteln. Als Ergebnis läßt sich vorwegnehmen: Die Wurzeln der transgenen Kunst tangieren zwar Body Art, Pop, Fluxus, Surrealismus, Dada, Futurismus und wohl auch Bauhaus ${ }^{30}$, aber ihre kunsttheoretische Nährlösung befindet sich in der Renaissance. Tatsächlich berufen sich Künstler wie Kac, TC\&A und Davis explizit auf die Frühe Neuzeit, allerdings unspezifisch, im vagen Sinne einer Verbindung von Kunst und Wissenschaft. Thomas Grünfeld verweist beiläufig auf Hieronymus Bosch als einzigen älteren Künstler, der ihn wirklich beeinflußt habe. ${ }^{31}$ Doch die Bezüge sind viel konkreter. Die künstlerischen und kulturtheoretischen Leitbilder der Chimärenkunst wurden in der Frühen Neuzeit ausgebrütet.

Gleich im ersten Paragraphen des ersten volkssprachlichen Malereitraktats, Cennino Cenninis Libro dell'arte von ca. 1400, wird das deutlich. Cennino, Enkelschüler Giottos, begründet hier in dem ansonsten weitgehend handwerkstechnisch orientierten Buch die Dignität der Malerei. Sie kann nie Gesehenes sichtbar machen. Der Maler ist frei wie der Dichter, alles zusammenzufügen und zusammenzubinden, was ihm gefällt (libero di potere comporre e legare insieme sì e no come gli piace, secondo sua volontà). Er kann eine Figur sitzend oder stehend ,komponieren' (zusammenfügen) oder aber eine Figur halb Mensch, halb Pferd herstellen (mezzo nomo

30 Vgl. dazu R. Hoppe-Sailer: Organismes/Art. Les racines historiques de l'art biotech, in: J.Hauser (Hg.): L'Art Biotech, Ausstellungskatalog Le Lieu Unique, Nantes (2003), Trézélan 2003, S. 86-91.

31 Vgl. F. Alfano Miglietti (Hg.): Virus Art. Viste e interviste dall rivista Virus Mutations, Mailand 2003, S. 259. 
mezzo cavallo).$^{32}$ Cennino paraphrasiert hier bekanntlich Horaz, der in seiner Ars poetica (ebenfalls zu Beginn) schreibt: „Ein Menschenhaupt mit Pferdes Hals und Nacken: denkt euch, so schüfe es die Laune eines Malers; dann trüge er buntes Gefieder auf, liehe aus allen Arten die Glieder zusammen: zu unterst wär's ein häßlich grauer Fisch, und war doch oben als ein schönes Weib begonnen. ${ }^{\text {"33 }}$ Horaz meint, daß bei seinem Mischwesen wohl jeder Zuschauer zum Lachen gereizt wird. Der Maler beruft sich dabei zurecht, wie der Dichter, auf die Freiheit seiner Phantasie. Zugleich zieht Horaz die Grenzlinien künstlerischer licentia: Zahmes mit Wildem, Lämmer mit Tigern oder Vögel mit Schlangen zu paaren, ginge zu weit. ${ }^{34}$ Damit ist Chimaera, die schauerliche Göttin, angesprochen, die Homer in der Ilias (VI, 181) als Mischwesen von Löwe, Schlange und Ziege schildert (Abb.9). Schon in der Antike gab es schreckliche und lustige Chimären.

Nach Cenninos Vorstoß ist es Leon Battista Alberti, der eine konsistente Ästhetik des ,Zusammenfügens' - der compositio - entwickelt. Bei Alberti ist damit das grundlegende Verfahren des Malers selbst bezeichnet, aus Einzelflächen Glieder, aus diesen Körper und zuletzt aus den Körpern den Kompositkörper des ,Vorgangs', der historia herzustellen. ${ }^{35}$ Im Anschluß

32 C. Cennini: Il libro dell'arte, hrsg. von F. Frezzato, Vicenza 2003, cap. 1 (S. 62).

33 Horaz: De arte poetica 1-13.

34 Zum Konzept künstlerischer licentia ausführlich: U.Pfisterer: Künstlerische potestas audendi und licentia im Quattrocento. Benozzo Gozzoli, Andrea Mantegna, Bertoldo di Giovanni, in: Römisches Jahrbuch der Bibliotbeca Hertziana 31, 1996, S. 107-148. Vgl. zum Zusammenhang von compositio, licentia und Chimären in der Kunsttheorie des 16. Jahrhunderts auch M. Thimann: Lügenhafte Bilder. Ovids 'favole' und das Historienbild in der italienischen Renaissance, Göttingen 2002, S. 43-48 und 63-71. Zum Verhältnis von decorum und compositio in der Architekturtheorie der Renaissance vgl. A. Payne: Mescolare, composti and monsters in Italian architectural theory of the Renaissance, in: L. Secchi Tarugi (Hg.): Disarmonia, bruttezza e bizzaria nel Rinascimento, Florenz 1998, S. 273-294.

35 Grundlegend: K. Patz: Zum Begriff der 'Historia' in L. B. Albertis 'De Pictura', in: Zeitschrift für Kunstgeschichte 49, 1986, S. 269-287. Zusammenfassende Überlegungen zum Begriff der compositio jetzt bei F. Fehrenbach: Lemma „Komposition“, in: U.Pfisterer (Hg.): Metzler Lexikon Kunstwissenschaft. Ideen, Methoden, Begriffe, Stuttgart - Weimar 2003, S. 178-183. 
an die antike Rhetorica ad Herennium (IV, xii, 18) meint compositio aber noch mehr: Das additive Verfahren des Zusammenfügens von Körpergliedern muß zugleich dissimuliert, die Übergänge sollen, weich' gestaltet werden, damit der Eindruck eines wirklichen Körpers entsteht. Das Vermögen und die Aufgabe des Malers - fingendis aut pingendis animantibus ${ }^{36}$ - hat also seine Pointe darin, das Getrennte so kunstvoll zu verbinden, daß gar nicht auffällt, daß es zuletzt aus Einzelformen bzw. Einzelgliedern besteht. Der Maler fügt, mit anderen Worten, das Getrennte so zusammen, daß der Körper nicht mehr aus Getrenntem zu bestehen scheint.

Albertis Ästhetik ist von dieser Idee des gottähnlichen Komponierens von schönen Körpern grundlegend geprägt, auch wenn bei ihm die fantasia keine eigenständige Rubrik darstellt und Chimären folglich in seinen künstlerischen Traktaten nicht erwähnt werden. Dennoch ist Alberti für unsere Frage nach den Ursprüngen der aktuellen und künftigen Kompositwesen von Bedeutung. Alberti meint, daß der Maler in jedem Fall die Natur nachahmen müsse, aber diese verteilt ihre Schönheiten höchst ungleich. Es geht also darum, die schönsten Teile auszuwählen und zu kombinieren. Als Beispiel verweist Alberti auf den Maler Zeuxis, der für ein Tempelbild die schönsten Körperteile von fünf schönen Jungfrauen der Stadt Kroton ausgewählt und daraus einen weiblichen Idealkörper komponiert habe. ${ }^{37}$ Die Anekdote selbst kombiniert entsprechende Abschnitte von Cicero und Plinius. ${ }^{38}$ Zeuxis schuf also aus fünf schönen menschlichen Leibern einen einzigen, schöneren, gemalten Körper.

Wie ernst es Alberti mit seinem Beispiel war, zeigt die Empfehlung seines kurzen Skulpturentraktates, als schön geltende Körperteile verschiedener Menschen zu vermessen, die Mittelwerte zu errechnen und mithilfe der Meßergebnisse dann Statuen herzustellen. ${ }^{39}$ Anthony Grafton wies zurecht darauf hin, daß Alberti hier - im Verständnis seiner Zeit - aus der Bild-

36 L. B. Alberti: De pictura II, 25.

37 Ebd. III, 56.

38 Cicero: De inventione II, 1; Plinius d.Ä., Historia naturalis XXXV, 64.

39 L. B. Alberti: De statua 4-12. 
hauerei eine Ingenieurskunst macht. ${ }^{40}$ Grafton zeigte aber auch, daß die ästhetische Kombinatorik in den Bereich der Biologie, genauer: der Tierzucht hineinreicht. Im satirischen Nachruf auf seinen Hund (Canis) von 1437 betont Alberti, daß Zeuxis die vollkommene Schönheit im Kopf des geliebten Tieres direkt vorgefunden und sich so der Umweg über die Jungfrauen erübrigt hätte. ${ }^{41}$ Dem vollkommenen Tier geht aber die Kombinationsgabe des Züchters voraus, wie Alberti im Leonello d'Este dedizierten Traktat über das "lebhafte Pferd“ (De equo animante) von 1443 darlegt. ${ }^{42}$ Gleich zu Beginn stellt Alberti die Einzelmerkmale vor, die der schöne, tüchtige Hengst besitzen muß, und welche Merkmale durch die Stute hinzukommen sollten, um den vollkommenen Nachwuchs - als Kompositwesen - zu erzeugen. Compositio ist so der Schlüsselvorgang, der Malerei und Pferdezucht verbindet; beides Tätigkeiten, wie Alberti betont, die dem Fürsten angemessen sind, dem Haupt und der verkörperten Bindekraft des gesellschaftlichen Kompositkörpers. ${ }^{43}$

Die Kehrseite dieser Diskurse über Körperkombinationen und Schönheit findet sich in Albertis Dialog Momus. Hier macht sich der Autor über seine eigene Kombinationsästhetik lustig und wünscht sich Ochsen mit Augen auf den Hörnern (um zielsicherer zu stoßen) und Häuser mit Rä-

40 A. Grafton: Leon Battista Alberti. Master Builder of the Italian Renaissance, London u.a. 2000, S. 336.

41 „Erat autem Canis noster facie honesta et liberali, liniamentiis a quibus Zeusis facile omnem pingendi venustatem et gratiam ut a virginibus crotoniatibus sumpsit, excepissent" (L. B. Alberti: Apologhi ed elogi, hrsg. von R. Contarino, Genua 1984, S. $156 \mathrm{f})$.

42 L. B. Alberti: De equo animante, hrsg. von A. Videtta, Neapel 1981, S. 106 f.

43 Vgl. dazu M. Warnke: Das Kompositbildnis, in: A. Köstler und E. Seidl (Hg.): Bildnis und Image. Das Porträt zwischen Intention und Rezeption, Köln u.a. 1998, S. 143149; H. Bredekamp: Thomas Hobbes visuelle Strategien. Der Leviathan: Urbild des modernen Staates, Berlin 1999, S. 76-82. Ferner: Th. DaCosta Kaufmann: Caprices of art and nature: Arcimboldo and the monstrous, in: E. Mai und J.Rees (Hg.), Kunstform Capriccio. Von der Groteske zur Spieltheorie der Moderne, Köln 1997, S. 33-52. 
dern (um schneller aus Gefahren zu entkommen). ${ }^{44}$ Albertis Momus deutet auf den Übergang zwischen einer regelgeleiteten kombinatorischen Schönheitslehre und der ungeregelten Kombinatorik der Phantasie. Ochsen mit augenbesetzten Hörnern - das ist der Bereich des Widernatürlichen und der Chimären. Es ist kein Zufall, daß zu Albertis Zeit in der italienischen Malerei die mittelalterlichen Drôlerien an den Seitenrändern der Manuskripte antikisierend umgebildet wurden und sich in der Architektur die Ornamentform der Grotteske ausbreitete (Abb. 10). Francesco di Giorgio etwa empfiehlt, Pilaster und Blendflächen mit dalfine, spiritelli [...] mostruosi animali, come se arpie zu schmücken. ${ }^{45}$ Vasari berichtet später im Rückblick auf die Entstehung dieser Ornamente, daß es sich um cose senza regola handle: appicando a un sottilissimo filo un peso che non si può reggere, a un cavallo le gambe di foglie, a un nomo le gambe di gru [!] ${ }^{46} \mathrm{Die}$ Grotteske schwelgt in Chimären.

Roland Kanz ist vor kurzem der Geschichte von Grotteske und Capriccio nachgegangen und hat dabei auch den erkenntnisgeschichtlichen Hintergrund dieser Kombinationskunst berührt. ${ }^{47}$ In den Mischformen von Tier, Mensch, Pflanze und Architektur dokumentiert sich nichts anderes als das Verfahren der fantasia. Es ist selbst stets ein kombinatorisches, das aus den Einzeldaten der Sinne oder den im Gedächtnis gespeicherten Bilder neue Kompositionen herstellt. Das wird häufig ,biologisch' gedacht, denn die kombinatorische Tätigkeit der Bilderherstellung geschieht in der ersten der drei Gehirnkammern, die relativ warm ist und damit das Ausbrüten

44 L. B. Alberti: Momus oder Vom Fürsten / Momus sen de principe, lat.-dt., übers., komm. und eingel. von M. Boenke, München 1993, S. 18-21.

45 F. di Giorgio Martini, Trattati de architettura civile e militare, hrsg. v. C. Maltese und L. Maltese Degrassi, Mailand 1967, Bd. 1, S. 65.

46 G. Vasari: Le Vite de' più eccellenti architetti, pittori, et scultori italiani, da Cimabue insino a' tempi nostri [...] Firenze 1550, hrsg. von L. Bellosi und A. Rossi, Turin 1991, Bd. 2, S. 73.

47 R. Kanz: Die Kunst des Capriccio. Kreativer Eigensinn in Renaissance und Barock, München und Berlin 2002, S. 54-80. 
der imaginativen Chimären begünstigt. ${ }^{48}$ Die Grotteske wird so zum Paradigma künstlerischer Freiheit.

Nun ist die Leidenschaft der Renaissance für die Grotteske zugleich damit verbunden, daß die Kombination von Körpern und Gattungen frei zwischen den Polen der Schönheit und des Lächerlichen beziehungsweise Monströsen zu schwingen vermag. ${ }^{49}$ Denn es darf nicht übersehen werden, daß die Mischwesen ursprünglich im Numinosen beheimatet sind. Vielleicht gehen auch die heraldischen Chimären auf apotropäische Ursprünge zurück. ${ }^{50}$ In christlicher Perspektive bezeichnen die Mischwesen meist die Verirrungen der dämonischen Schöpferkraft, in der die Kreation Gottes ihre karikierende Abwandlung erfährt. Die Möglichkeiten der Dämonen, in veränderlicher Gestalt zu erscheinen und reale Mischwesen zu erzeugen, sind beinahe unbegrenzt. Michael Cole zeigte jüngst, wie die Macht dieser pneumatischen Wesen auch in den Bereich der Phantasie, der unkontrollierten Einfälle und Bilder hineinreicht. ${ }^{51} \mathrm{Im}$ Traum führen sie das Spiel der Rekombination der Schöpfung aus. Der Satan wird meist als Mischwesen dargestellt - er ist ein capriccio (Abb.11).

An der Wortgeschichte des capriccio läßt sich die Wertverschiebung beobachten, die in der Renaissance stattfindet. Ursprünglich, etwa bei Dante, meint das Wort (als Verb: raccapricciare) den tödlichen Schreck, der die

48 Vgl. ebd. S. 60 (mit Hinweisen auf Juan Huarte).

49 Aufschlußreich etwa Cellinis Spott über den Helden von Baccio Bandinellis Hercules und Cacus, den er als "Löwenochsen“ (leonbue), mithin als capriccio karikiert; additive compositio, die sich auch im technischen Verfahren spiegelt (dua figure sole, mal fatte et tutte rattoppate); dazu D. Heikamp: Zum Herkules und Kakus von Baccio Bandinelli, in: R. Torella (Hg.): Le parole e $i$ marmi. Studi in onore di Raniero Gnoli [...], Rom 2001, S. 983-1006.

50 Vgl. der Hinweis bei W. Wunderlich, Dämonen: Monster, Fabelwesen. Eine kleine Einführung in Mythen und Typen phantastischer Geschöpfe, in: U. Müller und W. Wunderlich (Hg.): Dämonen, Monster, Fabelwesen, St. Gallen 1999, S. 11-38 (hier S. 26)

51 M. Cole: The demonic arts and the origin of the medium, in: The Art Bulletin 84, 2002, S. $621-640$. 
gekräuselten Haare zu Berge (capo riccio) stehen läßt. ${ }^{52}$ Seit dem Beginn des 16. Jahrhunderts setzt sich eine zweite Etymologie durch: der Sprung der Ziege (capra), die unerwartete Kombination des Getrennten - das Verfahren der Metapher, das Bewunderung hervorruft. Bei Vasari verbinden sich beide Stränge: das capriccio ist zugleich lustig, bizarr und terribile..$^{53}$

Schönheitskombinatorik und Capriccio bezeichnen die beiden Seiten einer einzigen Medaille. In beiden Fällen geht es um die Komposition von Körpern aus Einzelgliedern. Damit ist der Kern der Renaissanceästhetik berührt. Ihr kulturelles Gegenstück ist die massenhafte Verbreitung von Monster- und Prodigienliteratur, besonders im Cinquecento. ${ }^{54}$ Sie speiste sich aus der allgemeinen Grundüberzeugung von der biologischen Übergänglichkeit der Species und der Existenz unheimlicher Randvölker (Abb. 12). ${ }^{55}$ Bei Konrad von Megenberg finden sich bereits im 14. Jahrhundert erstaunlich modern anmutende Überlegungen zum Problem, ab wann ein Mischwesen als Mensch angesprochen werden könne. Konrad entscheidet sich für das Kriterium der Kopfform. ${ }^{56}$

Zuletzt ist es die Alchemie, Leitwissenschaft und Leidenschaft der Epoche, die sich - ähnlich wie die Kunsttheorie - für compositio als Herstellungsoption interessiert. Das wird schöpfungstheoretisch begründet: Auf-

52 Dante Alighieri: Divina Commedia, Inferno XIV, 76-78; XXII, 31. - Kanz [wie Anm. 47], S. $31 \mathrm{ff}$.

53 Vgl. die Zusammenstellung bei Kanz [wie Anm. 47], S. 87. Zur analogen Entkoppelung von Monstrosität und ethischem Charakter in der zweiten Hälfte des 16. Jahrhunderts: K.M. Brammal: Monstrous metamorphosis. Nature, morality, and the rhetoric of monstrosity in Tudor England, in: The Sixteenth Century Journal XXVII/1, 1996, S. 3-21.

54 Vgl. etwa H. Talkenberger: Sintflut. Prophetie und Zeitgeschehen in Texten und Holzschnitten astrologischer Flugschriften 1488-1528, Tübingen 1990; I. Ewinkel: De monstris. Deutung und Funktion von Wundergeburten auf Flugblättern im Deutschland des 16. Jahrhunderts, Tübingen 1995.

55 Vgl. H. Frübis: Die Wirklichkeit des Fremden. Die Darstellung der Nenen Welt im 16. Jahrhundert, Berlin 1995; J. Block Friedman: The monstrous races in medieval art and thought, Syracuse/NY 2000.

56 Vgl. Wunderlich [wie Anm. 50], S. 25. 
trag ist die Perfektion einer von Gott unvollendet gelassenen Kreation. ${ }^{57}$ Paracelsus bringt das im Buch Paragranum (1530) auf die lapidare Formel: „Die natur ist so subtil und so scharpf in iren dingen, das sie on grosse kunst nicht wil gebrauchet werden; dan sie gibt nichts an den tag, das auf sein stat vollendet sei, sonder der mensch muss es vollenden. Dise vollendung heisset alchimia. " 58 Shakespeare rühmt in $A$ Winter's Tale eine neugezüchtete Nelkenart: "[...] This is an Art / Which do's mend Nature: change it rather, but / The Art it selfe, is Nature." (IV, Z. 1906-1908).

Die neuplatonisch-aristotelisch geprägte Naturphilosophie der Renaissance kreist dabei um die Frage, was die Dinge und besonders die lebendigen Dinge zusammenhält, was aus dem Getrennten ein Kompositum macht (cogere in unum). Als bewirkende Substanz wird zumeist der calor innatus (bzw. vitalis, nativus) angesehen, ein Imponderabilium, das - nach Aristoteles - Bindekräfte freisetzt, als Klebstoff und im Klebstoff wirkt. ${ }^{59}$ An der technischen Unverfügbarkeit des calor innatus scheitern die zahlreichen Versuche, den Homunkulus herzustellen, wie etwa Francesco Bocchi resigniert feststellt. Lebendigkeit, so resümiert er im Blick auf Andrea del Sartos Werk, läßt sich technisch in der Kunst nur als ästhetischer Schein

57 Vgl. etwa Laktanz: De ira Dei 13, 2; Thomas von Aquin: Summa contra gentiles III, 22. Ein ähnliches Konzept in einer Programmschrift Vincenzo Borghinis; vgl. Ph. Morel: Le Studiolo de Francesco I de'Medici, in: Symboles de la Renaissance, Paris 1982, Bd. 2, S. 187-197.

58 Paracelsus: Das Buch Paragranum III, 2, zit. nach J. Huser (Hg.): Theophrastus Paracelsus. Bücher und Schriften, Hildesheim 1971, S. 61.

59 Vgl. E. Mendelsohn: Heat and Life. The Development of the Theory of Animal Heat, Cambridge MA 1964; G. Freudenthal: Aristotle's Theory of Material Substance. Heat and Pneuma, Form and Soul, Oxford 1995. Für die italienische Renaissance: M. Mulsow: Frühneuzeitliche Selbsterhaltung. Telesio und die Naturphilosophie der Renaissance, Tübingen 1998; F. Fehrenbach: Calor nativus - Color vitale. Prolegomena zu einer Ästhetik des 'Lebendigen Bildes' in der frühen Neuzeit, in: U. Pfisterer und M. Seidel (Hg.): Visuelle Topoi. Erfindung und tradiertes Wissen in den Künsten der italienischen Renaissance, Berlin und München 2003, S. 151-170. 
erzeugen. ${ }^{60}$ Die Herstellung einer ästhetischen Lebendigkeit ist das höchste Ziel, was sich in einer geradezu inflationären Verwendung des Lobtopos in der Renaissanceliteratur zeigt. Die Fiktionen der lebendigen Kunst markieren so auch ein biotechnologisches Desideratum, mal nostalgisch, mal utopisch.

Merkmalskombinatorik als Komposition des Getrennten und die Erzeugung des Lebendigen verweisen als zentrale ästhetische Leitbegriffe der Renaissance auf jenen ideellen Keimpunkt, aus dem das Phantasma der wirklichen Erzeugung von Chimären als Kunst bis heute sprießt. Francisco de Hollanda meint, daß die Betrachter von den lebendig gemalten Chimären seiner Zeit so begeistert seien, daß sie wünschten, so etwas möge auf Erden vorhanden sein. ${ }^{61}$ Transgene Kunst - sie steht schon in der Agenda der Frühen Neuzeit.

Nichts zeigt dies deutlicher als die künstlerische Transgression, die bei Vasari die Vita Leonardos verklammert. Das junge Genie wird von seinem Vater gebeten, ein Bild zu malen, das er dann einem Bauern schenken will. Der Vater überläßt das Thema dem Sohn. Leonardo zögert nicht lange und sammelt in der Natur höchst unterschiedliche Tiere ein - Schlangen, Eidechsen, Fledermäuse - aus deren Körperteilen er auf dem Bild eine Chimäre (einen Drachen, Abb.13) komponiert. Er ist so in die kombinatorische Arbeit vertieft, daß er den Gestank der verwesenden Tierkörper nicht wahrnimmt. Als der Vater das Bild abholen will, wird es von Leonardo so in Szene gesetzt, daß der Besteller glaubt, einem wirklichen Monster gegenüberzustehen und panisch die Flucht ergreift. Leonardo hält ihn zurück mit der trockenen Bemerkung, daß das Bild den Zweck, für den es gemalt wurde, erfüllt habe. Danach beginnt die Karriere des Meisters, der

60 F. Bocchi: Discorso sopra l'Eccellenza dell'opere d'Andrea del Sarto, Pittore fiorentino, in: Journal of the Warburg and Courtauld Institutes 52, 1989, S. 111-139 (hier 136-137; mit Verweisen auf Aristoteles); vgl. R. Williams: Art, theory, and culture in sixteenth-century Italy. From Techne to Metatechne, Cambridge 1997, S. 198 f.

61 F. de Hollanda: Quatro dialogos da pintura antigua (1548), dt.: Vier Gespräche über die Malerei gefübrt zu Rom 1538 (1548), übers. und komm. von J. de Vasconcellos, Wien 1899, S. 104-107; vgl. Kanz [wie Anm. 47], S. 198. 
in Vasaris Geschichtskonstruktion die Malerei auf die letzte und höchste Epochenstufe, die terza maniera, hebt. Hauptkennzeichen dieser Stufe ist Lebendigkeit, die sich unter anderem einer nie gesehenen Weichheit der Übergänge - mithin perfektionierter compositio! - verdankt. Allmählich nehmen bei Leonardo aber außerkünstlerische Interessen überhand; er erforscht Bewegungen, Sinnesaktivitäten, Lebensvorgänge. Vasari hält davon wenig und verweist auf die infinite pazzie, in denen sich Leonardo gegen Lebensende immer mehr verzettelte. „Dieser Künstler ging mit Giuliano de Medici nach Rom, zur Zeit der Erwählung von Papst Leo, welcher sich viel mit Philosophie und mehr noch mit Alchymie beschäftigte. [...] Einer seltsamen Eidechse, welche der Winzer von Belvedere fand, machte er Flügel aus der abgezogenen Haut anderer Eidechsen, die er mit Quecksilber füllte, so daß sie sich bewegten und zitterten, wenn sie ging; sodann machte er ihr Augen, Bart und Hörner, zähmte sie, tat sie in eine Schachtel und jagte all seinen Freunden damit solche Furcht ein, daß sie flohen. “62

Während der junge Leonardo noch mit der fiktiven Herstellung eines Monsters beschäftigt war, ,komponierte er im Alter ein wirkliches Lebewesen. Sind das die strani concetti e nove chimere, die Leonardo in der Malerei nicht mehr verwirklichen konnte, wie Baldassare Castiglione, der Leonardo während der Entstehungszeit des Cortegiano in Rom kennenlernte, meint? ${ }^{63}$ Lebendige Chimären standen wohl auch in Leonardos Agenda. Man muß es ernst nehmen, wenn er die Gottähnlichkeit des Malers mit dem göttergleichen Hervorbringen (generare) aller möglichen Wesen begründet, auch derjenigen, "welche die Natur noch niemals schuf" - und das sind unter anderen Monstrositäten (cose mostruose). ${ }^{64}$

62 G. Vasari: Leben der ausgezeichneten Maler, Bildhauer und Baumeister [...], übers. und bearb. von L. Schorn und E. Förster, Nachdruck Heidelberg 1983, Bd. III/1, S. 37 f. Vgl. P. Barolsky: Vasari and the historical imagination, in: Word and Image 15, 1999, S. 286-291.

63 B. Castiglione: Il libro del Cortigiano, hrsg. von A. Quondam, Mailand 1981, S. 179; vgl. E. Villata: „Strani concetti e nove chimere“. Leonardo e la pittura dell'invisibile, in: Rivista di estetica 37, n.s. 5, 1997, S. 69-85.

64 Leonardo da Vinci: Libro di Pittura, hrsg. von C. Pedretti, Florenz 1995, $\mathbb{} 13$. 
Der Zusammenhang zwischen der Erschaffung bzw. Neukombination von Lebewesen und der Selbstermächtigung des secundus Deus - farci vedere in terra novi Paradisi (Federico Zuccaro) ${ }^{65}$ - liegt auf der Hand; nirgendwo wird dieses kulturelle Programm der Frühen Neuzeit deutlicher formuliert als bei Francis Bacon. ${ }^{66}$ Als hätte es nie das alttestamentarische Verbot der Kreuzung verschiedener Arten gegeben (etwa: Leviticus 19, 19), kündigt der englische Großkanzler in seiner Nova Atlantis unbekannte Biofakte an: „Wir machen auch die einen [Tiere] künstlich länger und größer, als sie von Natur sind, andere wieder umgekehrt, zwergenhaft klein und nehmen ihnen ihre natürliche Gestalt [...] Auch in Farbe [sic], Gestalt und Gemütsart verändern wir sie auf vielerlei Weise $[\ldots]^{\text {“ }}{ }^{67}$

Nun sind der naive Augenaufschlag, die treuherzige soziale Geste und die spielerische Affirmation der Gentechnik ein offensichtliches Charakteristikum der bisherigen Transgenic Art. Joe Davis etwa kodiert die,weibliche altgermanische Fruchtbarkeitsrune in DNA und plant, die damit beglückten E.coli-Bakterien mit Hilfe von Satelliten in den Weltraum zu schießen, damit außerirdische Intelligenzen eine politisch korrekte Ergänzung des Uomo Vitrwviano Leonardos erhalten, der die NASA-,Missionen schon seit längerem begleiten darf. ${ }^{68}$ Edoardo Kac meint, daß die transgene Kunst in einer Welt des massenhaften Artensterbens einen Beitrag zur künftigen Biodiversität leisten könnte. Die künstlerische Subversion der Gentechnik findet bislang noch außerhalb der Transgenic Art statt, etwa in

65 D. Heikamp (Hg.): Scritti d'arte di Federico Zuccaro, Florenz 1961, S. 162 (L'idea de' pittori, scultori e architetti, Turin 1607).

66 Vgl. H. Bredekamp: Antikensehnsucht und Maschinenglauben. Die Geschichte der Kunstkammer und die Zukunft der Kunstgeschichte, Berlin 1993, S. 63 ff; ders.: Der Mensch als „zweiter Gott“. Motive der Wiederkehr eines kunsttheoretischen Topos im Zeitalter der Bildsimulation, in: K.P. Dencker (Hg.): Interface 1. Elektronische Medien und künstlerische Kreativität, Hamburg 1992, S. 134-147.

67 Zit. nach G. Engel: Zum Verhältnis von Utopie und Wissenschaft in Francis Bacons frühen Fragmenten, in: Karafyllis [wie Anm. 11], S. 27-40, hier S. 35.

$68 \mathrm{Vgl}$. http://www.viewingspace.com/genetics_culture/pages_genetics_culture/gc_w03/ davis_microvenus.htm. 
den breeding units Andrea Zittels ${ }^{69}$ oder in den Haarproben "from over 10,000 gifted individuals" von Gene Genies Worldwide. ${ }^{70}$ Der Kulturkritiker könnte es sich hier leicht machen und die bioartistische Avantgarde als Teil jener kolossalen Öffentlichkeitsoffensive ansehen, die von Seiten der sogenannten Spitzentechnologien seit den achtziger Jahren durchgeführt wird. ${ }^{71}$ Das erwünschte Ergebnis - ein breiter politischer und gesellschaftlicher Konsens darüber, technologische Innovationen selbst als Lösung der heutigen technikinduzierten Probleme herbeizusehnen und sich von einem normativen Naturbegriff zugunsten der totalen Machbarkeit und Kulturalisierung zu verabschieden - wurde inzwischen erreicht. In diesem Kontext verwundert die Bereitschaft der sogenannten Life Sciences kaum, Künstler als Botschafter der eigenen Reflexionsfähigkeit zu verwenden. Einer der Hauptsponsoren der Ars electronica 1999, der Vertreter von Novartis Austria, erklärte in seinem Grußwort mit entwaffnender Offenheit: „Gerade innovative Technologien bedürfen der gesellschaftlichen Akzeptanz, um ihr Nutzenpotenzial auch voll entfalten zu können. "72 Bei Davis, TC\&A oder de Menezes handelt es sich nicht nur um Künstler, denen großzügig der Zugang zu Laboratorien gewährt wird, die, unter enormem Zeitdruck

69 Vgl. http://www.zittel.org.

70 Vgl. http://www.genegenies.com/ggw.html ("The Creative Gene Harvest Archive began with Gene Genies Worldwide (c)(tm) and its intent to harvest, store, and utilize the genetic codes for creativity collected from some of society's most exemplary and recognized creative individuals in order to design and imbue future personalities with these same traits. In this display, we have selected a representative from over 10,000 gifted individuals who have made significant contributions to the arts and sciences over the past fifteen years. To gaze upon this collection is to be a witness to creativity, it is a truly significant work of art in its own right. The harvest is ongoing and the archive is under construction for being recognized as the eighth wonder of the world.")

71 Zum ökonomischen und politischen Hintergrund vgl. etwa J. Rifkin: The biotech century, New York 1998.

72 Ars electronica 99 [wie Anm. 10]. Der Text ist im Internet bequem zugänglich über: http://www.aec.at/de/archives/festival_archive/festival_catalogs/festival_artikel.asp? iProjectID=8320. 
stehend, wohl kaum von sich aus zu artistischen Spielereien neigen würden. Die genannten Künstler sind beziehungsweise waren vielmehr offiziell bestellte artists in residence des MIT, der Universität von Perth und des Clinical Sciences Centre im Imperial College London, also Hofkünstler großer Forschungseinrichtungen. Das läßt vielleicht die Unverkäuflichkeit ihrer Werke verschmerzen. Warum sollte das embedding reflexiver gesellschaftlicher Instanzen auf die Kriegsberichterstattung begrenzt bleiben?

Bio-Art - letztlich also doch bloß Kitsch, Propaganda, kunsthistorische Marginalie? ${ }^{73}$ Chimärenkunst, deren in vielfältiger Weise bescheidene Anfänge gerade zu beobachten sind, hat meines Erachtens Zukunft. Die triviale, gleichwohl gültige Feststellung, daß auf die Realisation des technisch Machbaren bislang kulturgeschichtlich noch selten verzichtet wurde, läßt an der Verbreitung der Gentechnik kaum zweifeln. „Vielleicht wird die Gesellschaft der Entfaltung überdrüssig und läßt aus Freiheit Möglichkeiten ungenützt, anstatt unter irrem Zwang auf fremde Sterne einzustürmen "74 diese Hoffnung Adornos bleibt wohl angesichts der ungebrochenen technologischen Dynamik unrealistisch. Die Gentechnik macht in diesem Szenarium keine Ausnahme. Wenn die ersten medizinischen Erfolge absehbar oder unabdingbar sind (etwa nach mikrobiologischen Katastrophen), wird sich jene Lawine weiter beschleunigen, die vertraute Wertvorstellungen seit längerem rapide begräbt. Schon heute gehen bekanntlich nur noch wenige wegen In-vitro-Fertilisation oder menschlichem Insulin, das in Schweinen gezüchtet wurde, auf die Barrikaden. Übermorgen wird kaum jemand auf

73 Vgl. W. Kemp: Über die Straßenglaubwürdigkeit von Kunst, in: Merkur 638, 2002, S. 508-512.

74 Th. W. Adorno: Minima Moralia: Reflexionen aus dem beschädigten Leben. Frankfurt/M. 1981, Aphorismus 100 (Sur l'eau). 
biotechnisch gezüchtete Ersatzteile verzichten wollen. Das ästhetische shaping greift schon jetzt breit über die Fitneßstudios auf die Operationssäle über und könnte mithilfe des genetic engineering sogar die stillgestellte Evolution des menschlichen Genotyps, unabhängig von der sexual choice, wieder ,anspringen ${ }^{6}$ lassen. ${ }^{75}$ Solange der rapide Wertzuwachs des symbolischen Kapitals ,Attraktivität' anhält, wird, wer es sich leisten kann, zunehmend medizinische Verjüngungstechnologien nutzen (müssen). Bildergeschichte und Kunst bleiben damit aber als phantasmatische Motoren im Spiel. Zugleich ist die Gentechnik selbst eng genug mit gestaltgebenden, performativen, plastischen und farbigen Resultaten verknüpft, um das Interesse der Künstler geradezu zwangsläufig auf sich zu ziehen.

Mehr noch: Genetic engineering hat mit dem Leben, seiner Umgestaltung und seinen Rändern zu tun und ruft damit unvermeidlich eines der dauerhaftesten Paradigmen der Kunst auf. Gerade der Schwund und die Übergänglichkeit eines emphatischen Begriffs von Leben (gegenüber dem biochemischen Paradigma) bringen älteste ästhetische Leitbilder ins Spiel. ${ }^{76}$ Ästhetische Lebendigkeit spielte seit jeher an der Grenze zwischen totem Artefakt und scheinbarer, vexierbildhafter Lebendigkeit. Leonardo etwa konstatiert, daß dem Artefakt das natürliche Leben fehlt, weshalb man es mit einem künstlichen, akzidentiellen Leben ausstatten müsse. ${ }^{77}$ Francesco Bocchi lobt - mit Giulio Camillo - die ägyptischen Bildhauer dafür, an eine Grenze gegangen zu sein, angesichts derer die Lebenskräfte, eigentlich' gar nicht anders konnten, als den skulpturalen Leib zu beseelen. ${ }^{78}$ Lebendige Kunstwerke befinden sich stets in einem Sprung hin zur wirklichen Beseelung; ihre Oszillation zwischen inertem Material und scheinbarer Wahrnehmungsfähigkeit, Bewegung, Leiblichkeit macht jenen Kern von Faszi-

75 Menninghaus [wie Anm 14], S. 234 ff.

76 Vgl. den Überblick bei Fehrenbach: Metzler Lexikon Kunstwissenschaft [wie Anm. 35], S. 222-227.

77 „Dove manca la vivacità naturale, bisogna farne una accidentale“ (Leonardo da Vinci: Il Codice Atlantico di Leonardo da Vinci nella Biblioteca Ambrosiana di Milano, bearb. von A. Marinoni, 24 Bde., Florenz 1973-80, fol. 399 recto).

78 Bocchi [wie Anm. 60]. S. 138; vgl. Williams [wie Anm. 60], S. 199. 
nation und Enttäuschung aus, den die Ekphrasen aller Zeiten variieren. Gerade also die biomechanische Stoßrichtung der gegenwärtigen Lebensforschung aktualisiert jene delikate Grenze von tot und lebendig, an der sich bildende Kunst seit der Antike vielfältig abarbeitet.

Die Konsequenz dieser Aktualisierung bestünde im Offenhalten der rezeptiven Übergänge zwischen totem Artefakt und lebendigem Individuum. Ein (inzwischen sogar verfilmtes ${ }^{79}$ ) Beispiel mag dies erläutern: An einem Abend im November 2002 kündigte eine junge Frau im Berliner Künstlerhaus Tacheles ihren Selbstmord an. ${ }^{80}$ Anwesende Künstler filmten und fotografierten die Verzweifelte. Ein Bewohner nahm sich der Frau an und fuhr sie gegen Morgen nach Hause. Die Lebensmüde kehrte aber zurück und stürzte sich unbemerkt aus dem fünften Stock. Am frühen Morgen besuchte ein deutsches Rentnerehepaar den morbiden hot spot, fand die Leiche im Hof und fotografierte sie. Eine gleichzeitig hinzukommende italienische Schulklasse war vom Anblick entsetzt. Die lachenden Rentner beruhigten Schüler und Lehrer mit dem abgeklärten Hinweis darauf, daß es sich hier doch um eine Kunstaktion handeln müsse. Beim Näherkommen erfaßten und erfaßte die Betrachter die Wahrheit. Hier interessiert der beschriebene kategoriale Sprung. Auch wenn das Ehepaar niemals etwas von Anna Mendieta gehört haben sollte, überrascht doch, wie abgeklärt auf eine Situation reagiert wurde, die vor dreißig Jahren noch Aufsehen erregte. Mendieta stellte sich selbst einem teilweise nichtsahnenden Publikum als verblutetes Vergewaltigungsopfer dar (Rape/Murder, 1973). ${ }^{81}$ Heute beherrscht jeder Kaffeefahrer das selbstreflexive Spiel der Einbildungskraft, sobald die Vorzeichen auf ,Kunst' gestellt sind.

Die Reaktion des Publikums zeigt einen Sprung zwischen interessierter Annäherung (totes Artefakt) und entsetzter Distanzierung (toter Organismus). Unter biomechanischen Prämissen dürften sich die Perspektiven

79 "Janine F.“ (2004); Regie: Teresa Renn.

80 Vgl. Tagesspiegel Berlin, 4.11.2002.

81 O. Viso: Anna Mendieta. Earth body. Sculpture and performance, 1972-85, Ausstellungskatalog, Whitney Museum, New York u.a. (2004-2006), Ostfildern (Ruit) 2004. 
eigentlich kaum unterscheiden. Offensichtlich legt der Betrachter dem lebendigen (oder ursprünglich lebendigen) Organismus aber etwas bei, was die Perspektive auf Nichtorganisches radikal invertiert. Das geht weit über die letztlich wieder beherrschbare Evokation des Return of the Real hinaus, den Hal Foster noch 1996 mit Blick auf den New Neurotic Realism etwa von Damian Hirst und Marc Quinn propagierte. ${ }^{82}$ Die angesprochene rezeptive Leistung ließe sich stattdessen gut mit Überlegungen zur Autopoiesis von Lebewesen begründen, wie sie zwischen Kant, v. Uexküll, Francisco Varela und zuletzt Andreas Weber entwickelt wurden. ${ }^{83}$ Hans Jonas bietet mit seinen Texten über Organismus und Freibeit entscheidende biophänomenologische Grundlagen, auch wenn seiner existenzialontologisch geprägten Perspektive die Interaktion von Lebewesen nur als blinder Fleck eingeschrieben ist. ${ }^{84}$ Die Autonomie jedes Organismus, die sich als Selbsterhaltung äußert und im Stoffwechsel geregelt ist, prägt unser Vorverständnis des Lebendigen. Wenn ein Objekt als lebendig erkannt wird, dann entsteht im Betrachter eine Distanz, die sich auf die Anerkennung jener ,Innerlichkeit' und der damit verbundenen unablässigen Wertgenerierung zurückführen läßt.

Eben damit ist, so wäre zu vermuten, das rezeptive Feld der aktuellen und künftigen Bio-Art bezeichnet. Die Artefakte, um die es sich hier handelt, besitzen zugleich jene Selbstbezogenheit (nach Jonas „Freiheit“), an der sich der Blick des Betrachters irritierend bricht. Die jetzigen und künf-

$82 \mathrm{H}$. Foster: The return of the real. The avant-garde at the end of the century, Cambridge MA u.a. 1996; vgl. dazu kritisch U.Frohne: Berührung mit der Wirklichkeit. Körper und Kontingenz als Signaturen des Realen in der Gegenwartskunst, in: H. Belting u.a. (Hg.): Quel corps? Eine Frage der Repräsentation, München 2002, S. $401-426$.

83 A. Weber: Natur als Bedeutung. Versuch einer semiotischen Theorie des Lebendigen, Würzburg 2003; vgl. auch E. von Samsonow: Der Körper als Passage. Meditation über das Wachsen, in: Belting [wie Anm. 82], S. 175-187 und K. Köchy: Perspektiven des Organischen. Biophilosophie zwischen Natur- und Wissenschaftsphilosophie, Paderborn u.a. 2003.

84 H. Jonas: Organismus und Freibeit. Ansätze zu einer philosophischen Biologie, Frankfurt/M. 1997. 
tigen Biofakte erlauben das reflexive Spiel der interesselosen ästhetischen Urteilskraft nur bis zu einer bestimmten Grenze, besser: sie untergraben dieses Spiel fortwährend. Das Werk führt, jenseits der künstlerischen Produktion und jenseits der rezeptiven Aneignung ein Eigenleben, an dem auch die Bestimmungen gut trainierter Rezipienten moderner Kunst abprallen. Als nicht (allein) von Menschenhand gemachte Gebilde, als buchstäbliche acheiropoieta treten diese Werke ins Leben über und bringen Grenzen ins Schwingen, an denen mitten im künstlich Erzeugten eine Alterität erscheint, die mannigfaltige Reaktionen entbindet, etwa - um im Rahmen ,vorästhetischer ${ }^{c}$ Kunsterfahrung zu bleiben - Furcht und Mitleid. Inmitten der totalen kulturellen Mobilmachung, inmitten der aktuellen Auflösung jeder natürlichen Alterität, könnte die Nichtverfügbarkeit des Außermenschlichen erneut triumphieren, pessimistisch: als Schöpfung, die sich gegen ihre Schöpfer stellt; optimistisch: durch Chimären, die uns poetische Rätsel stellen und die alte Verwandtschaft von Organismus und Schönheit reformulieren. ${ }^{85}$ An diesem Punkt werden wir die sogenannte Selbstreferenzialität der Kunst und die sportliche Selbstgenügsamkeit ihrer modernen Rezipienten aber hinter uns gelassen haben.

$\approx$

Ich schließe mit zwei Zitaten aus dem Zeitalter vor der Biokunst. Joseph Beuys, lapidar wie immer: „Es darf nicht nur eine Kommunikation zwischen den Menschen geben, sondern sie muß auch mit anderen Wesen stattfinden. " 86 Sigmund Freud an die griechische Prinzessin Marie Bonaparte über einen seiner beiden Chows (Brief vom 6.12.1936): „Und bei aller Fremdartigkeit der organischen Entwicklung doch das Gefühl einer innigen

85 Vgl. J. Bilstein und M. Winzen: Das Tier in mir. Die animalischen Ebenbilder des Menschen (zugl. Ausstellungskatalog, Staatliche Kunsthalle Baden-Baden, 2002), Köln 2002.

86 Zit. nach: Herausforderung Tier [wie Anm. 21], S. 30. 
Verwandtschaft, einer unbestrittenen Zusammengehörigkeit. Oft, wenn ich Jofi gestreichelt, habe ich mich dabei ertappt, eine Melodie zu summen, die ich ganz unmusikalischer Mensch als Arie aus dem ,Don Juan' erkennen mußte: Ein Band der Freundschaft bindet uns beide [...] " (Abb. 14) ${ }^{87}$

87 Dazu ausführlich: M. Bonaparte: Topsy, der goldhaarige Chow, übers. von A. und S. Freud, Frankfurt/M. 1981. 

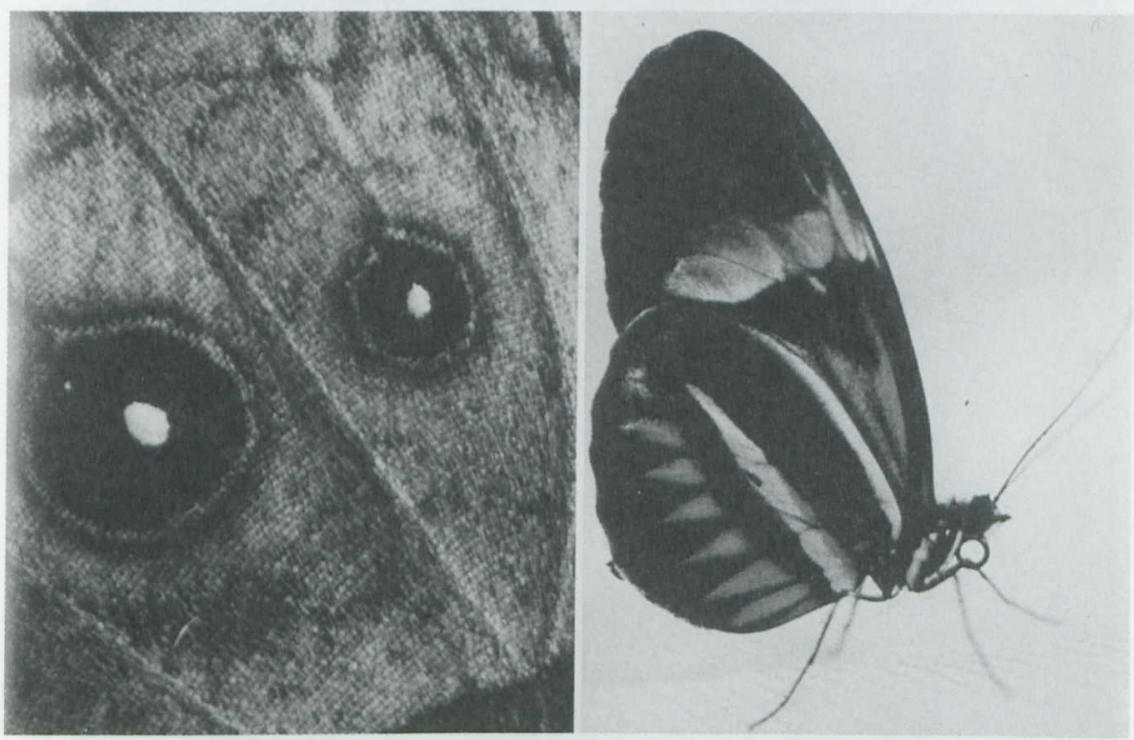

Abb. 1 Marta de Menezes, Nature?, 2000. 




Abb. 2 Stelarc, The extra ear, Fotomontage, 1997. 


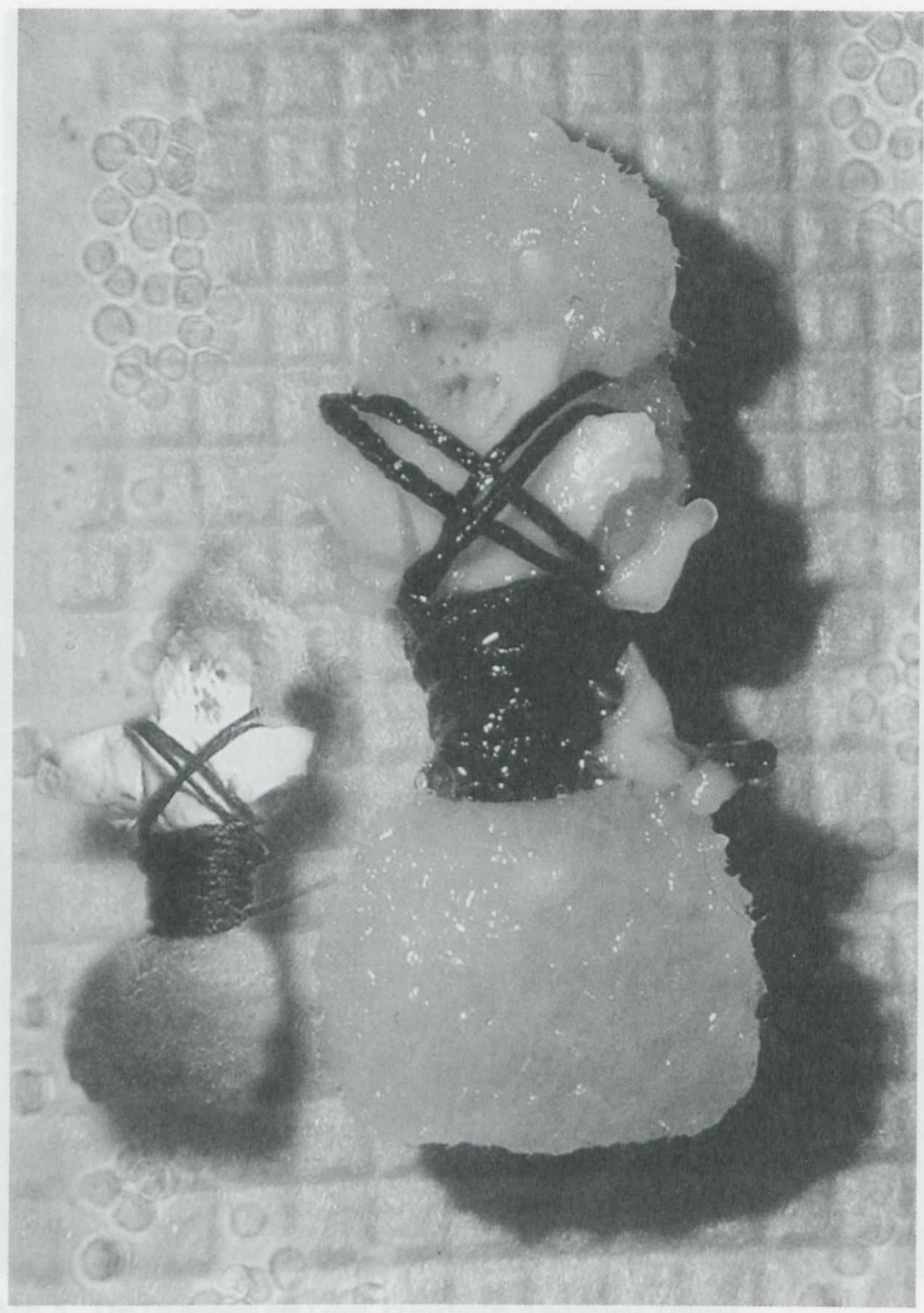

Abb. 3 Tissue, Culture \& Art, Semi-living worry dolls, 2003. 




Abb. 4 Edoardo Kac, GFP Bunny, 2000. 


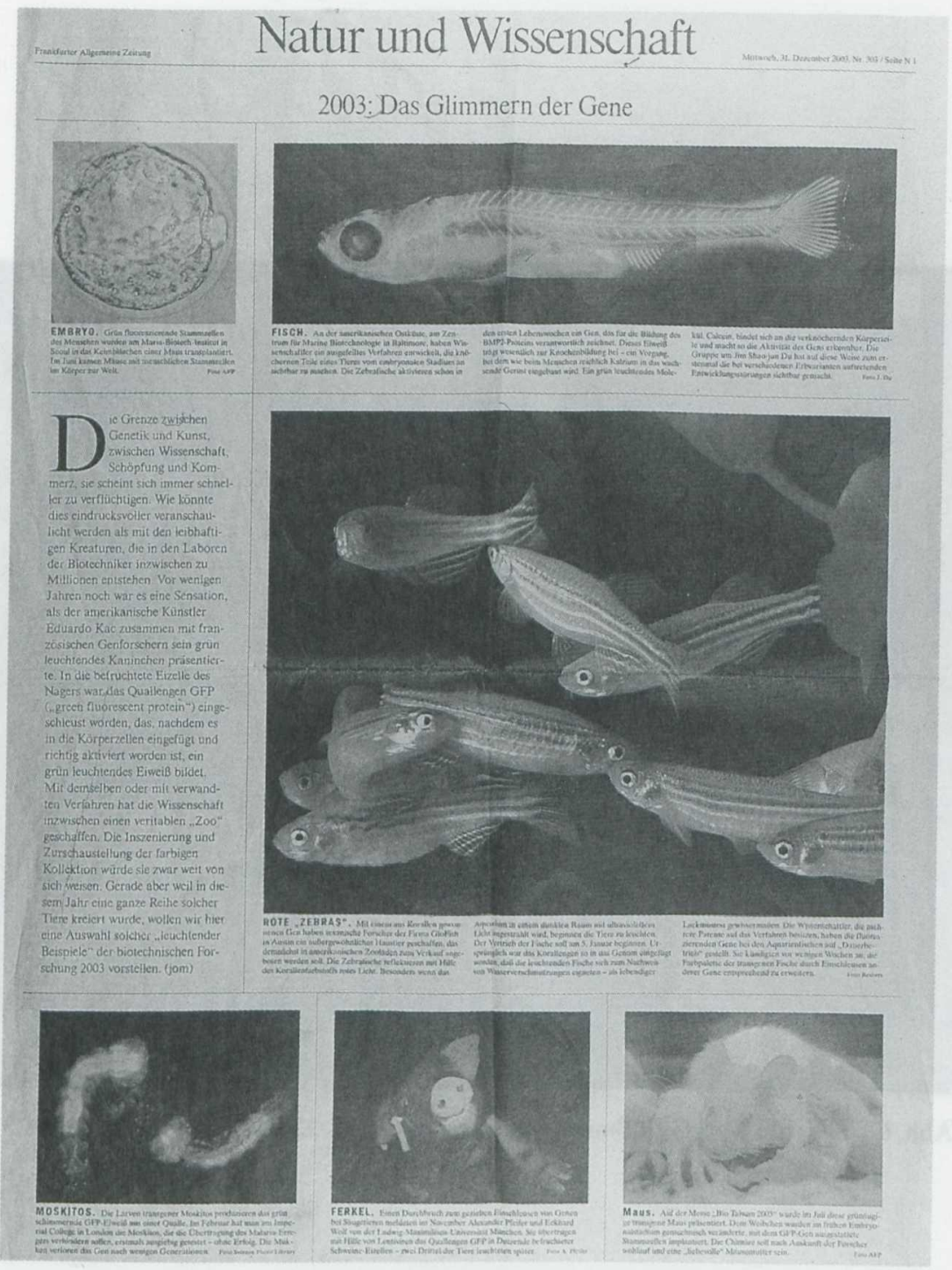

Abb. 5 Das Glimmern der Gene, Frankfurter Allgemeine Zeitung, Nr. 303 (31. 12. 2003), S. N1. 


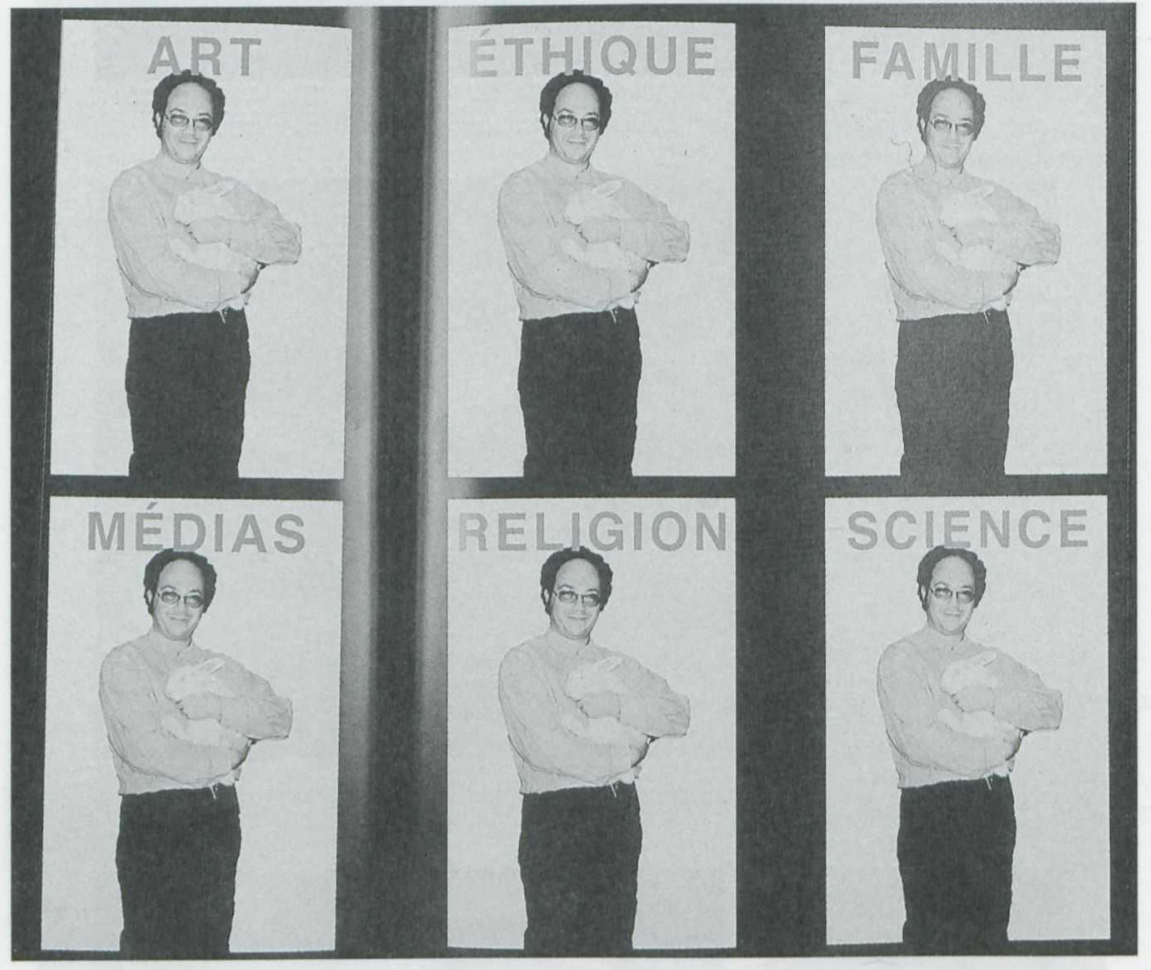

Abb. 6 Edoardo Kac, GFP Bunny - Paris Intervention, 2000, Plakataktion in Paris. 




Abb. 7 Joseph Beuys, Wie man einem toten Hasen die Bilder erklärt, Aktion, 1965, Galerie Schmela, Düsseldorf. 


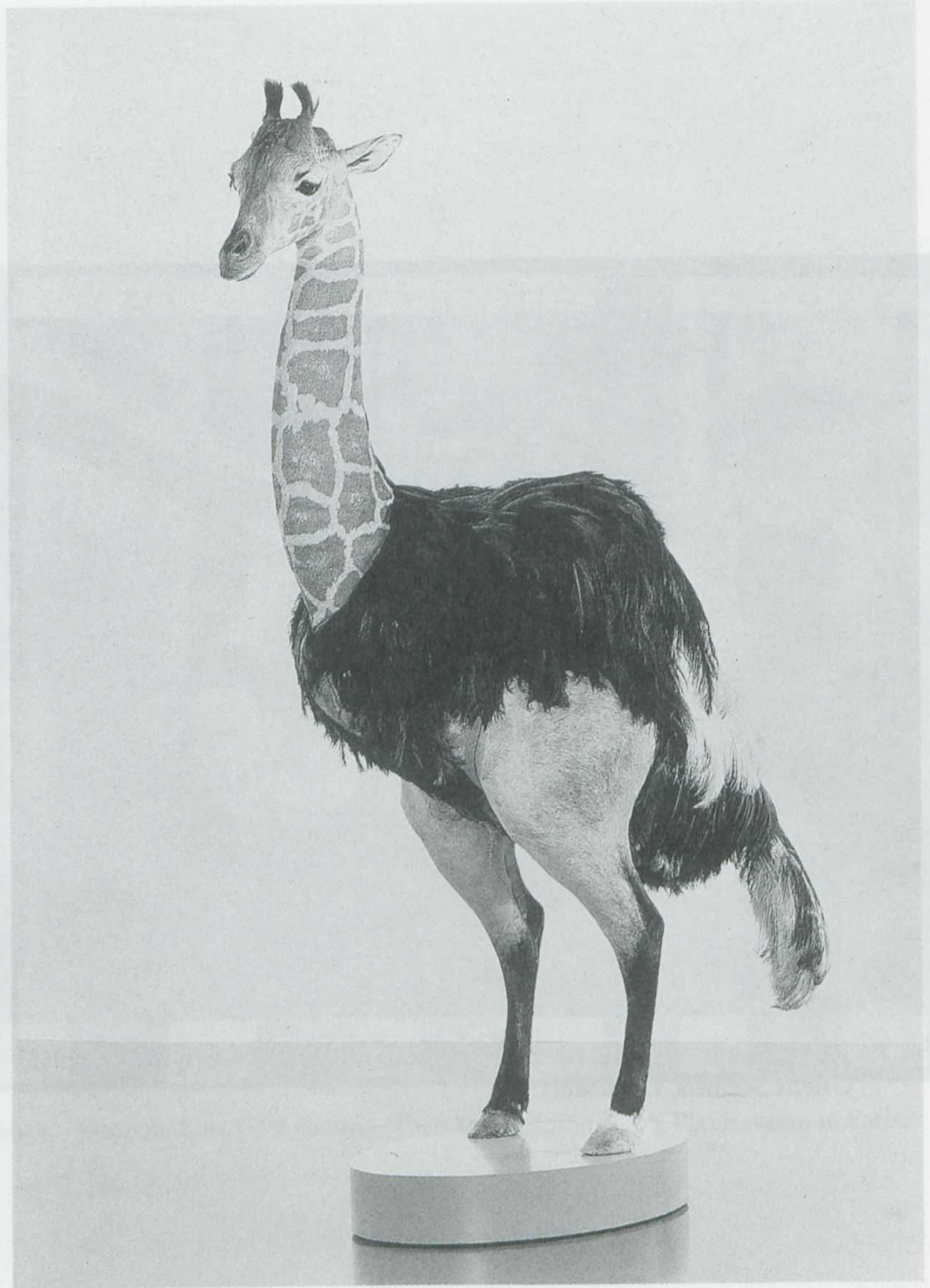

Abb. 8 Thomas Grünfeld, Misfit (Giraffe 00/32), 2000. 


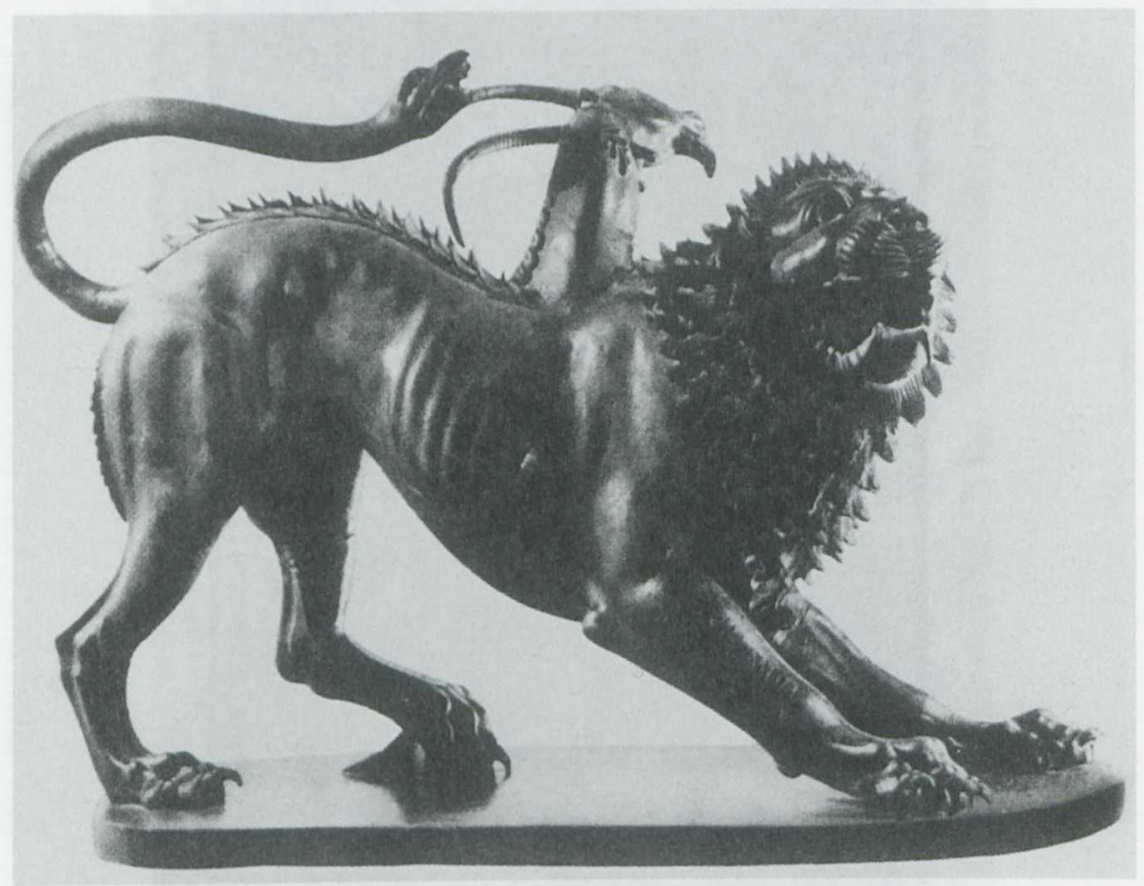

Abb. 9 Chimäre, etruskisch, 5. Jh. v. Chr., Florenz, Museo Archeologico. 




Abb. 10 Filarete und Antonio Bonfini, Trattato di architettura, Venedig, Biblioteca Nazionale Marciana, cod. Marc. Lat VIII, 2 (2796), 1488/89, Incipit, Detail. 


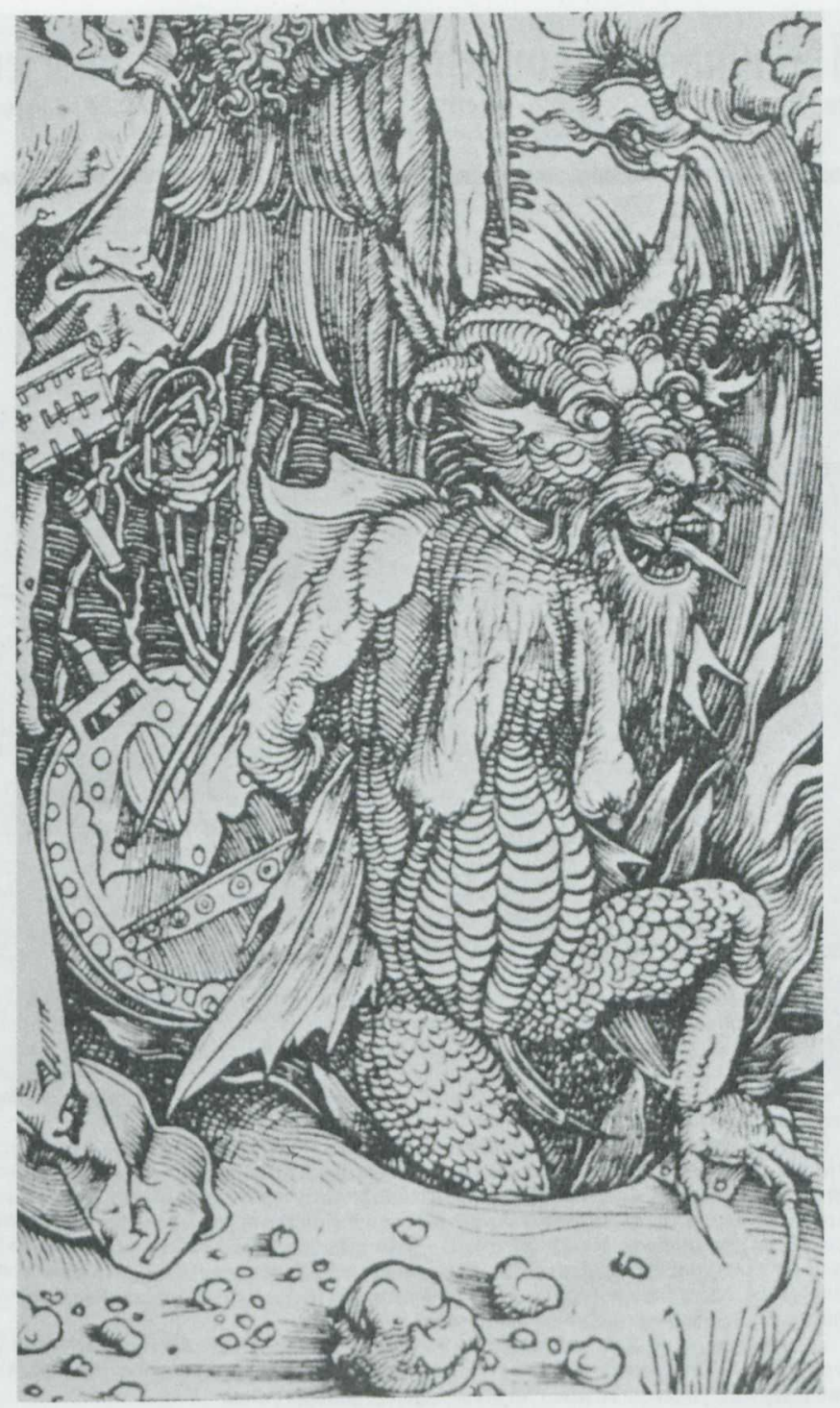

Abb. 11 Albrecht Dürer, Der Engel mit dem Schlüssel zum Abgrund, Detail, Apokalypse, Holzschnitt, 1497/98. 


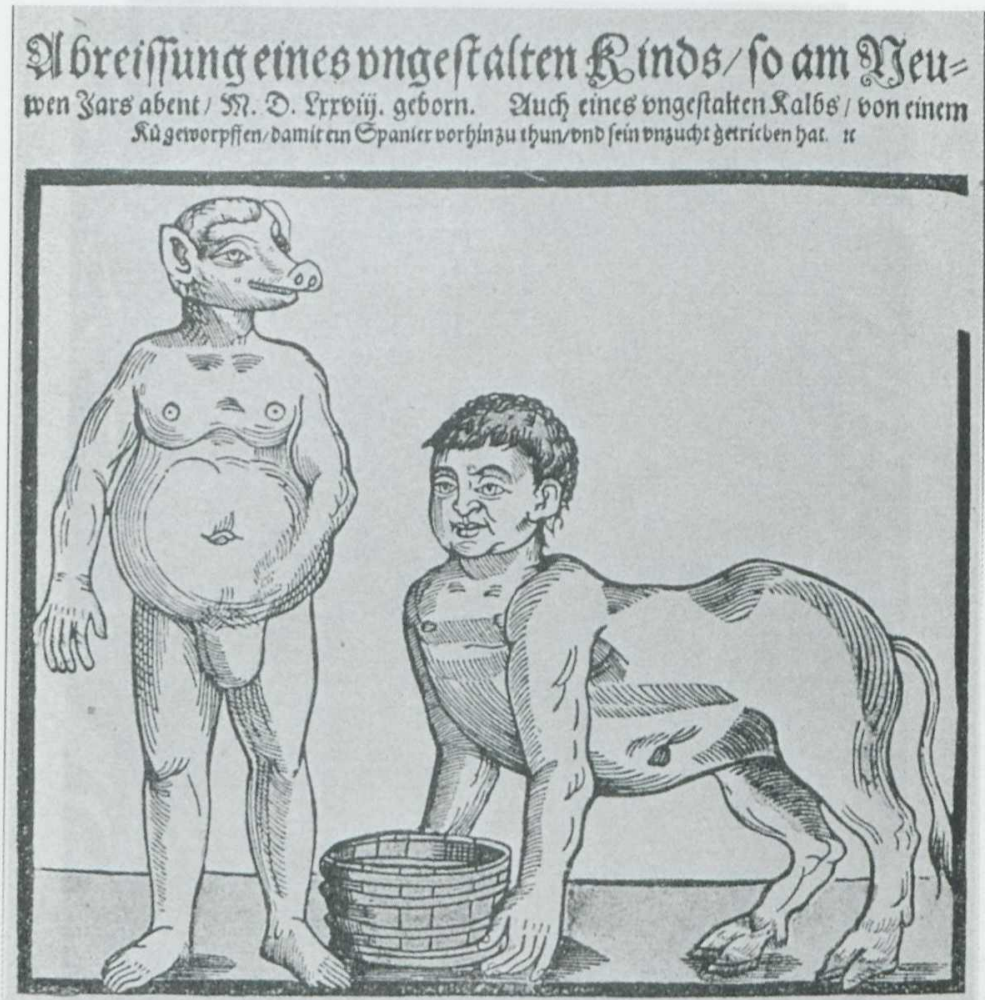

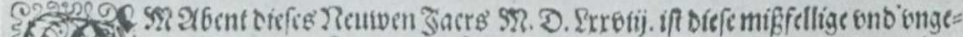



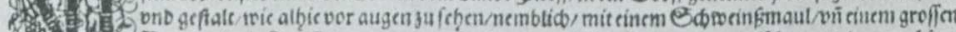

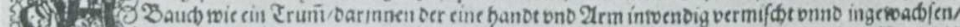

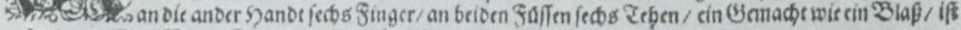

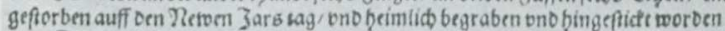

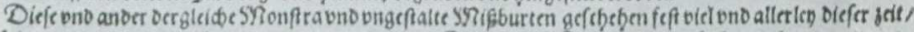

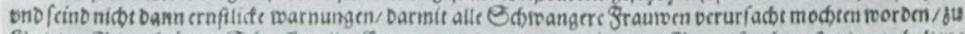

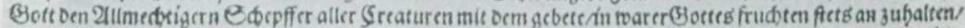

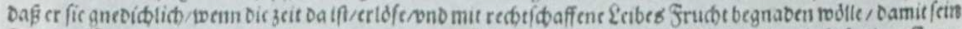



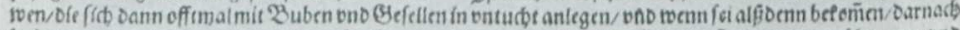

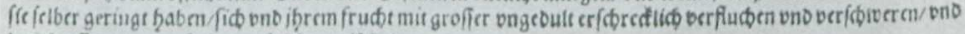
Damit of imal berurfarben zu fulchen mifffalten arburten.

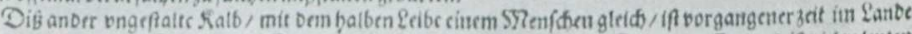

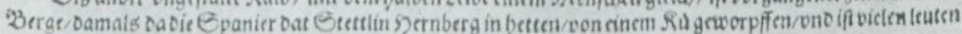

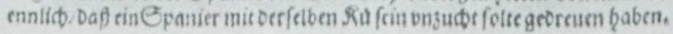

Abb. 12 Anonym, Abreißung eines ungestalten Kindes, Holzschnitt, 1587. 


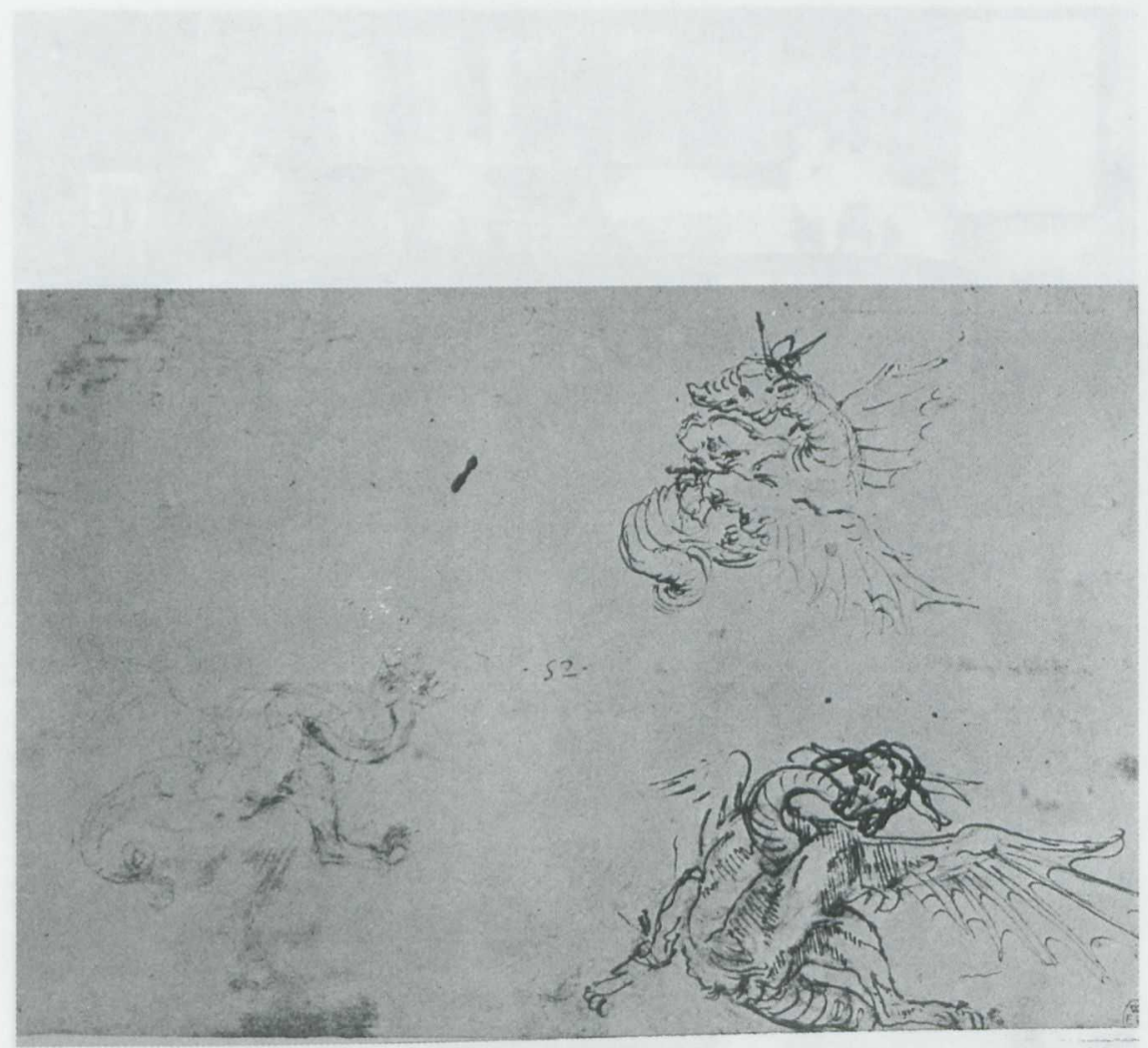

Abb. 13 Leonardo da Vinci, Studien für einen Drachen, um 1480, Windsor, Royal Library, Inv. 12370. 


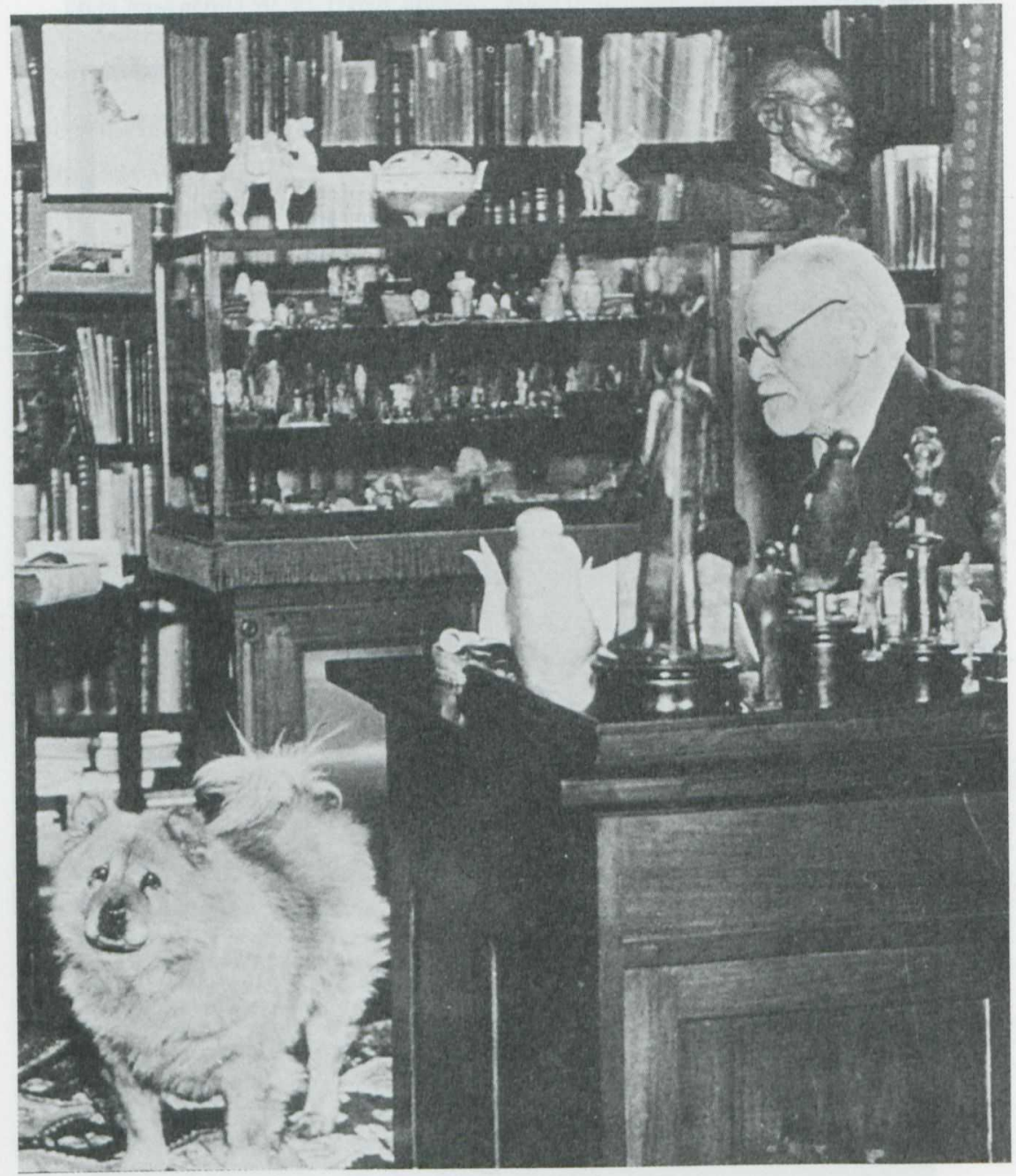

Abb. 14 Sigmund Freud in seinem Wiener Arbeitszimmer, um 1936. 


\section{ABBILDUNGSNACHWEIS}

\section{Fehrenbach}

Archiv des Autors: Abb. 5, 9

(C) Kupferstichkabinett, Berlin: Abb. 11

(c) Zentralbibliothek, Zürich: Abb. 12

(C) Royal Library, Windsor Castle (Inv. Nr. 12370 recto): Abb. 13

Abbildungen aus Publikationen:

J. Hauser (Hg.): L'Art Biotech', Ausstellungskatalog Le Lieu Unique, Nantes (2003), Trézélan 2003: Abb. 1, 3, 4 http://www.stelarc.va.com.au/extra_ear/index.htm: Abb. 2

R. Heller (Hg.): Unter der Haut. Ausstellungskatalog LehmbruckMuseum, Duisburg, 2001: Abb. 6, 8

J. Bilstein und M. Winzen: Das Tier in mir. Die animalischen Ebenbilder des Menschen (zugl. Ausstellungskatalog, Staatliche Kunsthalle BadenBaden, 2002), Köln 2002: Abb. 7 (Foto: U. Klophaus)

J. Rykwert und A. Engel (Hg.): Leon Battista Alberti. Ausstellungskatalog, Palazzo Te, Mantua (1994), Mailand 1994: Abb. 10

E. H. Gombrich: Tributes. Interpreters of our cultural tradition, Oxford 1984: Abb. 14 